\title{
Clinical Impact of the Epithelial-Mesenchymal Transition in Lung Cancer as a Biomarker Assisting in Therapeutic Decisions
}

\author{
Julien Ancel ${ }^{a, b} \quad$ Maxime Dewolf ${ }^{b}$ Gaëtan Deslée ${ }^{a, b} \quad$ Béatrice Nawrocky-Raby ${ }^{a}$ \\ Véronique Dalstein ${ }^{\mathrm{a}, \mathrm{c}} \quad$ Christine Gilles $^{\mathrm{d}}$ Myriam Polette $^{\mathrm{a}, \mathrm{c}}$

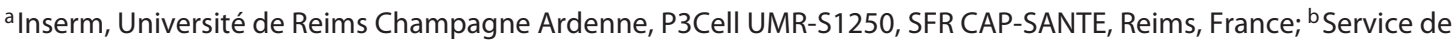 \\ Pneumologie, Hôpital Maison Blanche, CHU de Reims, Reims, France; ' Laboratoire de Pathologie, Hôpital Maison \\ Blanche, CHU de Reims, Reims, France; ' ${ }^{2}$ Laboratory of Tumor and Development Biology, GIGA-Cancer, University of \\ Liège, Liège, Belgium
}

\section{Keywords}

Non-small-cell lung cancer · Epithelial-mesenchymal transition · Therapy · Resistance

\section{Abstract}

Lung cancer is one of the most common solid cancers and represents the leading cause of cancer death worldwide. Over the last decade, research on the epithelial-mesenchymal transition (EMT) in lung cancer has gained increasing attention. Here, we review clinical and histological features of non-small-cell lung cancer associated with EMT. We then aimed to establish potential clinical implications of EMT in current therapeutic options, including surgery, radiation, targeted therapy against oncogenic drivers, and immunotherapy.

๑) 2020 S. Karger AG, Basel

\section{Introduction}

Lung cancer is responsible for the highest number of cancer-related deaths world wide. About $85 \%$ of lung cancers are classified as non-small-cell lung cancers (NSCLC), which are histologically subdivided into adenocarcinoma (AC) (about half of NSCLC cases) and squamous cell carcinoma (SCC) (about $30 \%$ of NSCLC cases). Regarding staging, more than half of the cases are diagnosed at a metastatic or advanced stage without curative options. Over the past years, innovative therapies such as molecularly targeted drugs and immunotherapies, have emerged and have led to overall improvements in cancer treatment. However, global 5-year survival rate for NSCLC patients remains under 20\% [Hirsch et al., 2017; Bray et al., 2018]. Even in localized stages with a surgically resectable tumor, 5-year survival rates drastically drop from $60 \%$ for stage IIA disease to $36 \%$ for stage IIIA disease according to the 8th edition staging project of the International Association for the Study of Lung Cancer (IASLC) [Goldstraw et al., 2016]. Promising and innovative strategies are ongoing, especially in neoadjuvant [Uprety et al., 2020] and adjuvant [Broderick, 2020; NCT02595944; NCT02486718; NCT02504372] contexts, which could improve the dramatic landscape of NSCLCs [Otaibi et al., 2019; Kris et al., 2020]. Nevertheless, this fateful prognosis also highlights the need to further refine tumor characteristics in order to improve clinical patient management.

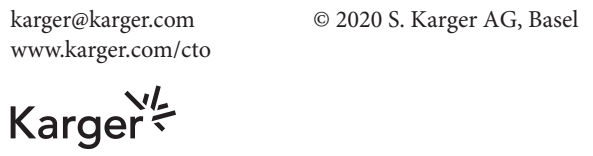


Research on the epithelial-mesenchymal transition (EMT) in lung cancer has gained major interest in the last decade. EMT is a term widely used now to describe the loss of epithelial features and the acquisition of mesenchymal traits by epithelial cells in various physiological and pathological conditions. In cancer, EMT is considered as a dynamic and reversible process, thereby generating various phenotypes. Some hybrids may have enhanced plasticity allowing them to adapt to various tumor microenvironments (TMEs) encountered during cancer progression and metastatic dissemination [Dongre and Weinberg, 2019; Bhatia et al., 2020; Yang et al., 2020]. As such, EMT has been shown to endow tumor cells with many properties that may provide them a selective advantage to master different steps of cancer progression, including enhanced invasive potential, enhanced survival, stimulation of angiogenesis, immune escape, resistance to apoptotic signals, and niching properties [Francart et al., 2018; Pastushenko and Blanpain, 2019]. EMT is molecularly complex, diversified, and context dependent. This complexity certainly contributes to slow down the implementation of EMT consideration in clinical routine. EMT programs may indeed be triggered by several factors, such as transforming growth factor- $\beta$ (TGF- $\beta$ ) [Miyazono et al., 2018], fibroblast growth factor (FGF) [Katoh and Nakagama, 2014], epidermal growth factor (EGF) [Shaurova et al., 2020], Notch, or Wnt signaling pathways [Yuan et al., 2014; Patel et al., 2019]. Activated signaling pathways converge onto a set of transcription factors, such as Snail, ZEB, and Twist family [Zeisberg and Neilson, 2009]. A dynamic balance finally represses expression of epithelial-related genes such as E-cadherin and induces expression of genes coding for mesenchymal markers such as vimentin. Importantly, EMT rather supports early steps of the metastatic dissemination, i.e., tumor invasion, survival in the blood stream, and early niching. After an eventual period of dormancy, a reversal towards more epithelial phenotypes, so-called mesenchymal-epithelial transition (MET), is considered to occur at secondary sites to support metastatic outgrowth. Although EMT features have been described for many years in numerous histological types of cancer, discussion remains regarding EMT characterization in tumors. Pancancer studies are based on most consensual and proposed canonical markers, such as E-cadherin ( $C D H 1)$, vimentin (VIM), $\mathrm{N}$-cadherin $(\mathrm{CDH} 2)$, and fibronectin (FN1). Using NSCLC cell lines and tumor samples, some studies established EMT signatures. From these NSCLC reports, some markers such as DSP, TJP1, CLDN4,ERBB3, GALNT3, and CDS1 appear commonly associated with
CDH1 epithelial-related genes while $M M P-2, A X L$, ZEB1/2, NRP-1, and TWIST clustered with VIM and FN1 mesenchymal-related genes [Wushou et al., 2014; Zheng and Kang, 2014; Antony and Huang, 2017; Goossens et al., 2017; Wong et al., 2018; Karacosta et al., 2019; Shao et al., 2019].

We discuss here the potential utility of examining and considering EMT in clinical practice. Although some reports highlight a contribution of EMT in small-cell lung cancer [Ito et al., 2017] and malignant pleural mesothelioma [Schramm et al., 2010] with specific implications respective to their cell type origin, we will focus this review on NSCLC, the most frequent lung cancer in which EMT has now been extensively analyzed. We aim at pointing to clinically relevant features related to the EMT process that could help clinicians to identify disease contexts. We further propose to examine the beneficial contribution of EMT in the clinical management of early/ advanced stages to metastatic conditions in order to meet current clinical challenges. Considering the poor outcome of resectable lung cancer, a crucial challenge is indeed to identify independent and powerful predictors of global patient outcomes that are currently lacking. On the hand, advanced and metastatic conditions are associated with inevitable therapy resistance to currently available strategies, including chemotherapies, radiotherapy, targeted therapies, and immunotherapies. In these clinical conditions, considering EMT as a biomarker could allow a refinement of patient management.

\section{NSCLC Biomarkers Related to EMT}

Aiming at defining the clinical relevance of EMT as a biomarker, we will first confront the EMT status with pathological features of lung tumor cells, and then unravel relationships bridging EMT to two cornerstones of both lung carcinogenesis and clinical management that are oncogenic drivers and immune profiles.

\section{EMT and Histopathological Features}

The literature emphasizes that EMT features are quite commonly observed in lung cancer both in AC and in SCC [Kidd et al., 2014; Mittal, 2018]. For example, in a study by Dauphin et al. [2013], up to $50 \%$ of tumor cells had a mesenchymal phenotype. Mesenchymal traits were shown to be even more frequent in other lung histological types, such as large-cell neuroendocrine carcinomas [Galván et al., 2014], sarcomatoid carcinomas [Thomas et al., 2012], or pleomorphic carcinomas, which are typi- 


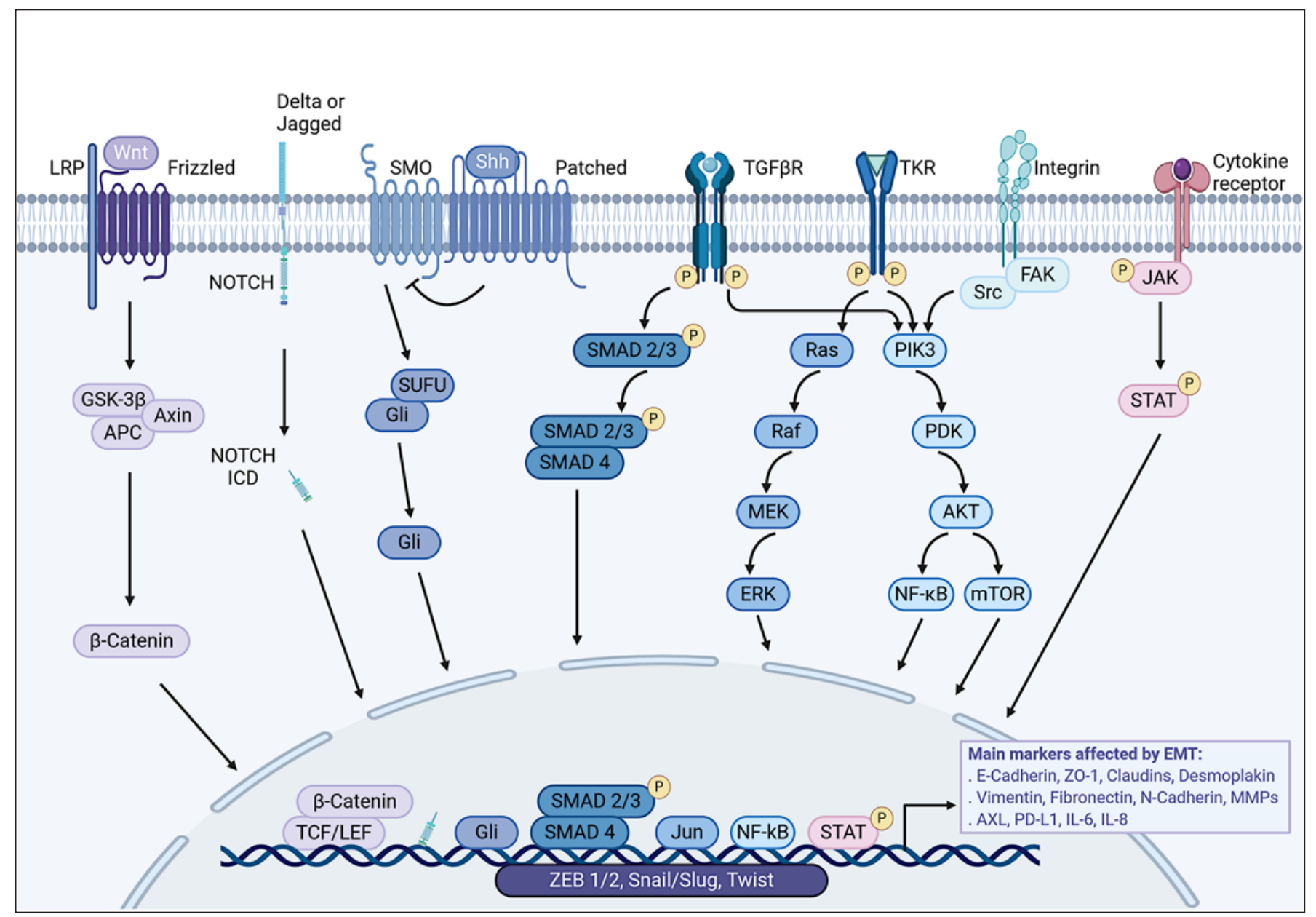

Fig. 1. Main EMT markers and activation pathways. Major actors of main signaling pathways involved in EMT are represented. APC, adenomatous polyposis coli; ERK, extracellular signal-regulated kinase; FAK, focal adhesion kinase; GSK-3 $\beta$, glycogen synthase kinase- $3 \beta$; ICD, intracellular domain; JAK, Janus kinase; LRP, lipoprotein receptor-related protein; MMPs, matrix metalloproteinases; mTOR, mechanistic target of rapamycin kinase; NF- $\kappa B$, nuclear factor $\kappa B$; $P$, phosphorylation; PDK, pyruvate de- hydrogenase kinase; PD-L1, programmed death ligand 1; PI3K, phosphatidylinositol kinase; Shh, sonic hedgehog; SMO, smoothened; STAT, signal transducers and activators of transcription; SUFU, suppressor of fused homolog; TCF/LEF, lymphoid enhancer factor/T cell factor; TGF $\beta$ R, transforming growth factor $\beta$ receptor; TKR, tyrosine kinase receptor; ZO-1, zonula occludens-1. This figure was created with BioRender.com. cally reflect the mesenchymal switch [Miyahara et al., 2015; Kondo et al., 2018]. Mesenchymal features have also been associated with a low degree of differentiation in NSCLC [Dauphin et al., 2013; Matsubara et al., 2014; Bian et al., 2019; Z. Wang et al., 2019]. Otherwise, the spatial distribution of EMT features within a tumor is very heterogenous. EMT attributes have thus frequently been reported in so-called invasive fronts, at the interface with extracellular matrix, correlating with invasiveness and metastatic potential [Maeng et al., 2014]. EMT has also been associated with hypoxic zones and inflammationrich areas [Dominguez et al., 2017], emphasizing a major contribution of specific TMEs in EMT induction/regulation [Yang and Wu, 2008; Hung et al., 2009; Foster et al., 2014]. Accordingly, experimental data strongly support that EMT may be induced/regulated by extracellular matrix components, inflammatory mediators, and other soluble factors secreted by stromal cells, and hypoxia [Lou et al., 2016; Mittal et al., 2016]. Inversely, EMT-positive tumor cells have also been reported to secrete higher levels of soluble factors crucially impacting TME (e.g., VEGF stimulating angiogenesis, chemokines impacting immune cell recruitment). Finally, effects on the immune system are classically examined clinicopathological pa- 
rameters in lung cancer. Thus, EMT also modulates immune cell infiltration [Dominguez et al., 2017; De Matteis et al., 2019] through well-identified molecular regulatory networks [Markopoulos et al., 2019]. For instance, Chae et al. [2018] reported reduced CD4 T-cell and CD4/CD8 $\mathrm{T}$-cell infiltration in lung AC and SCC, respectively, with tumor cells displaying mesenchymal attributes (EMT positive). Inversely, increases in activated B cells and regulatory $\mathrm{T}$ cells were reported, although some differential infiltration patterns need to be further defined between AC and SCC. Additionally, EMT-positive tumors were also found to overexpress multiple immunosuppressive cytokines, such as IL-10, TGF- $\beta$, IL-6, or IL-11 [Q. Zhang et al., 2017; Zhao et al., 2018; Jiang et al., 2019; Zheng et al., 2019]. A narrow crosstalk and regulatory loops between stromal cells and EMT-derived cells are thus established, contributing to the formation of particular areas favoring tumor invasion and dissemination. Main EMTassociated markers and activation pathways are illustrated and summarized in Figure 1.

In addition to EMT determination in lung primary tumors, examining EMT in circulating tumor cells (CTCs) has also gained major interest. Presently, CTCs indeed appear as promising biomarkers in lung cancer [Y. Li et al., 2018; Milano et al., 2018; Maly et al., 2019]. Unlike tumor biopsies, CTCs allow a live assessment of disease progression and could thus help to predict metastasis and monitor therapeutic response. Today, numerous studies report the presence of EMT-shifted hybrid CTCs and CTC clusters in NSCLC patients [Lindsay et al., 2017; G. Li et al., 2018; Sawabata et al., 2020]. Interestingly, Manjuntha et al. [2019] observed that the intensity of EMT marker staining (vimentin and fibronectin) was higher in EMT-positive CTCs than in patient-matched NSCLC tumor tissues. Validating the importance of EMT characterization and supporting its utility for clinicians, Wu et al. [2015] classified CTCs into 3 subpopulations (epithelial, intermediate, and mesenchymal phenotypes) and reported that mesenchymal CTCs were more commonly found in patients in the metastatic stages of different types of cancers. Additionally, several reports associated a mesenchymal shift in CTCs as predictor of a poor outcome in NSCLC [Li et al., 2017, p. 4; Liu et al., 2018]. Miguel-Perez et al. [2019] thus identified mesenchymal CTCs as an independent prognostic factor for relapsefree survival, with an impact on overall survival in resected lung ACs. Moreover, similar data were obtained in a prospective and controlled cohort [Manjunath et al., 2019]. Among metastatic stages, EMT subclassification could allow to further refine those with a poor evolution profile [Y. Wang et al., 2019]. EMT status in CTCs could also be useful as a predictor of therapeutic response [Liao et al., 2014; Togo et al., 2017; Milano et al., 2018]. Despite these numerous data validating the clinical relevance of examining EMT in CTCs, the variability of methodologies used to enrich and isolate CTCs combined with the molecular complexity of EMT certainly introduces biases in our comprehension of EMT-related CTC heterogeneity. It seems worth mentioning that many CTC isolation devices are based on the expression of specific epithelial biomarkers (such as EpCAM). Subpopulations of EMTderived CTCs, supposedly expressing lower levels of many membrane epithelial markers, may thus fail to be detected by such methods. To address this limitation, alternative enrichment devices exploiting physical properties of CTCs are developed to isolate label-free CTCs and facilitate the study of EMT heterogeneity in the CTC population [Alix-Panabières et al., 2017; Nicolazzo et al., 2019; Genna et al., 2020].

All in all, EMT is a frequent event in NSCLC, which is observable both at the primary tumor site and in CTCs. Its association with unfavorable clinicopathological features justifies the proposition to consider EMT as a potential marker to predict patient outcome. Methodological standardization and identification of the most relevant molecular markers are nevertheless necessary steps before routine clinical application.

\section{EMT and Oncogenic Drivers}

Our growing molecular knowledge of cancer somehow shook some dogmas and continuously redirects lung cancer management. Several targeted therapies constitute the current arsenal to combat lung cancer, most of which are specifically directed against recognized oncogenic drivers of lung cancer (Fig. 2). Among major genetic modifications associated with NSCLC, KRAS, EGFR, and ALK, addictive mutations or alterations are probably the main ones [Arbour and Riely, 2019].

\section{KRAS}

To date, KRAS mutation is the most common molecular alteration encountered in NSCLC but remains with no effective therapies targeting tumors harboring the mutant KRAS variant despite many clinical trials [Aran and Omerovic, 2019; Yang et al., 2019]. Experimental data suggest that KRAS mutations contribute to mesenchymal changes, either alone, but often also combined with other EMT-inducing factors [Arner et al., 2019]. For instance, mutant KRAS and TP53 cell lines established from a lung cancer transgenic mouse model were found to display im- 


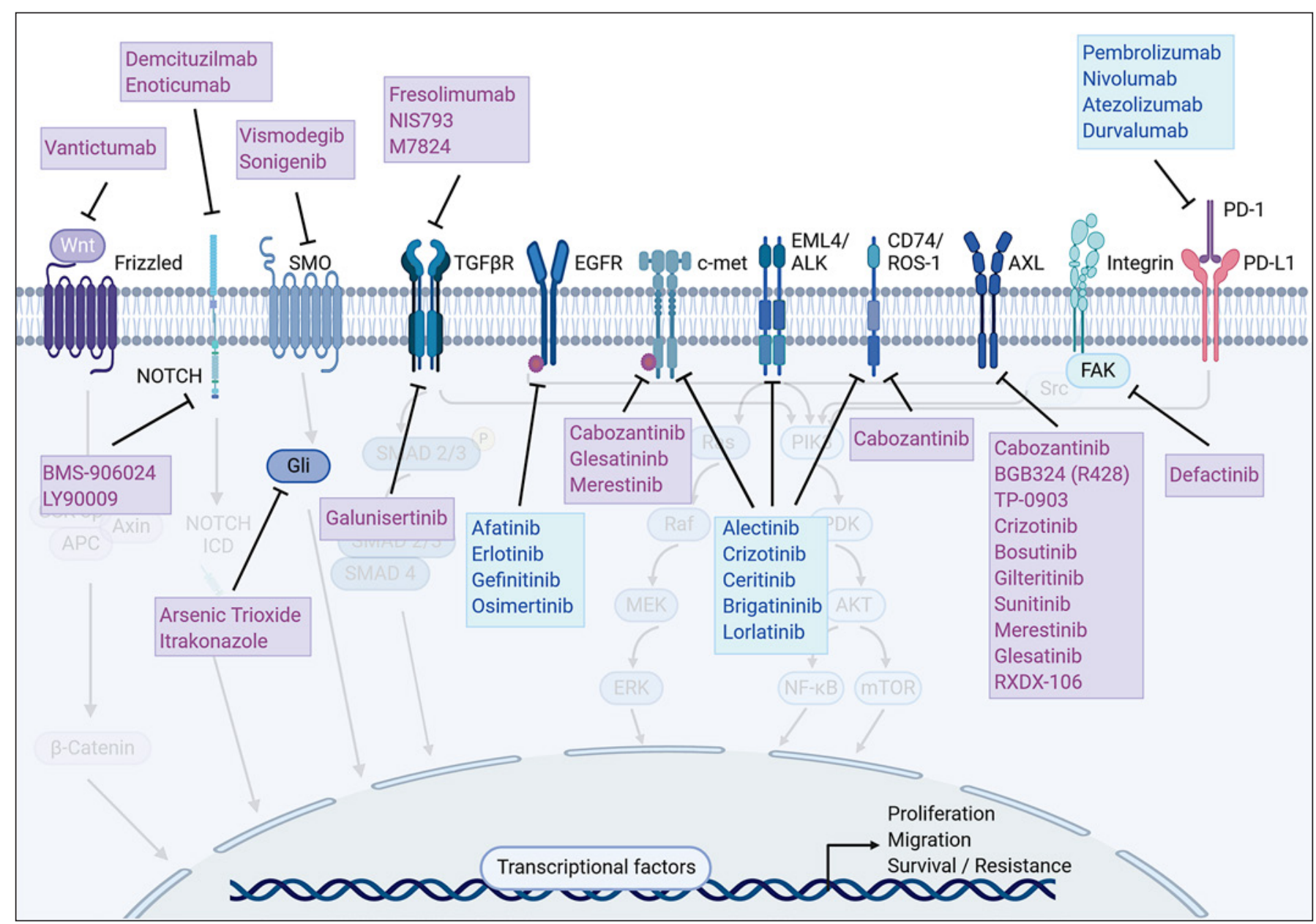

Fig. 2. Inhibitors currently used in NSCL management. Inhibitors promisingly analyzed in clinical trials are also depicted. Drugs currently available and used in lung cancer management with potential impact on EMT are depicted in blue. Additionally, drugs in pink represent molecules in development of potential interest as
EMT inhibitors in NSCLC. EML4/ALK, echinoderm microtubuleassociated protein-like 4/anaplastic lymphoma kinase fusion. See legend to Figure 1 for further abbreviations. This figure was created with BioRender.com. portant EMT/MET plasticity. A shift towards a mesenchymal phenotype was shown to depend on a welldescribed miR-200/ZEB regulatory loop and to promote metastasis [Gibbons et al., 2009]. Deciphering further KRAS mutant/EMT relationships, Singh et al. [2009] showed that, within KRAS mutant cell lines, 2 subgroups were distinguished based on their KRAS dependency to maintain their viability. In contrast to the untreated cell line, the KRAS-dependent NSCLC cell line treated with the classical EMT inducer (TGF- $\beta 1$ ) acquired KRAS independency. Thus, mesenchymal-switched NSCLC cell lines harbor KRAS independency and, inversely, support a close relationship between EMT and loss of oncogene addiction. Examining KRAS molecular status and EMT phenotype as tandem biomarkers could thus harbor a particular significance and also refine patient stratification and therapeutic strategies. Considering until now deceiving effectiveness for drugs targeting KRAS addiction, selected patients with KRAS-mutant NSCLC harboring the epithelial phenotype could thus benefit from KRAS inhibitors.

\section{EGFR}

As the second most common molecular addiction occurring in NSCLC, activating mutations of the EGF receptor (EGFR) gene are especially involved in lung ACs without smoking history. A large majority of these activating mutations (85-90\%) occurs by exon 19 deletion 
(about 45\%) or exon 21 L858R mutation (about 45\%) [Castellanos et al., 2017]. In EGFR-mutated advanced lung cancer patients, many randomized phase III trials have revealed that treatment with first-, second-, and now third-generation EGFR tyrosine kinase inhibitors (TKIs) resulted in improved outcome compared to standard first-line chemotherapy [Soria et al., 2018]. Erlotinib even provided efficacy similar to chemotherapy as second-line therapy in EGFR wild-type tumors with no additional adverse events [Ciuleanu et al., 2012]. However, cancer progression is fatal after a median 12-month treatment, and almost all patients who strongly responded to EGFRTKIs acquire resistance over time. Frequently, the mechanism of resistance is an acquired EGFR mutation [Rotow and Bivona, 2017]. In half of the cases, this second mutation is a T790M point mutation in exon 20 of the EGFR gene [Kobayashi et al., 2005] that can be triggered by osimertinib, a dedicated EGFR-TKI [Carlisle and Ramalingam, 2019]. In patients with a tumor harboring a mutation in EGFR and developing EGFR-TKI resistance, a significant part does not exhibit mechanisms of genotypic resistance. Such an EGFR-independent mechanism of resistance includes EMT, which occurs in about $5 \%$ of cases [Bronte et al., 2018; Lim et al., 2018]. Interestingly, tumors from patients developing resistance to TKIs exhibit mesenchymal traits while maintaining their original EGFR-activating mutation. Moreover, Sequist et al. [2011] did not observe EMT features in patients developing a resistance mechanism mediated by a T790M EGFR mutation, supporting that T790M does not drive EMT. In patients harboring a T790M mutation and treated with osimertinib, unfortunately, progression also occurs, and a C797S tertiary mutation has been identified. A tertiary resistance could be also associated with and/or supported by EMT, even in non-C797S mutation-harboring patients, although MET gene amplification may more frequently drive the underlined mechanism of resistance in this context [Del Re et al., 2019]. Those clinical observations linking EGFR-TKI resistance to the emergence of EMT phenotypes are supported by in vitro and in vivo preclinical studies [Tulchinsky et al., 2019; X. Zhu et al., 2019]. For example, TGF- $\beta 1$, insulin-like growth factor 1 receptor (IGF1R), and Notch-1 pathways, known to be potent EMT inducers, seem to be crucial actors in resistance mechanisms [Rho et al., 2009; Suda et al., 2011; Cortot et al., 2013; Xie et al., 2013; Soucheray et al., 2015; Zhou et al., 2015]. This phenotypical switch appears to be reversible and could thus be promising in combined therapies [Witta et al., 2006]. By using dasatinib, Sesumi et al. [2017] inhibited EMT induction by TGF- $\beta$ in EGFR-mu- tant NSCLC cell lines. For NSCLC already harboring erlotinib resistance with mesenchymal features, dasatinib monotherapy failed to restore both an epithelial phenotype and sensitivity to EGFR-TKIs. However, combining erlotinib and dasatinib prevented EMT-mediated resistance to EGFR-TKI and resulted in T790M mutation resistance.

\section{ALK}

Among molecular alterations in ALK, ALK translocations with a fusion partner correspond to the second targetable oncogenic driver to date in NSCLC [Du et al., 2018]. Following the ALEX trial, alectinib became the gold standard of ALK-rearranged related TKIs with an increase in overall survival [Hida et al., 2017]. As similarly observed in EGFR inhibitor management, some ALK inhibitor resistance inevitably occurs and is mediated most of the time by an acquired $A L K$ mutation [Katayama, 2018]. As for resistance to EGFR-TKI, EMT has been observed and proposed as a nononcogenic resistance pathway [Peters and Zimmermann, 2018]. Gainor et al. [2016] explored different mechanisms of ceritinib resistance in 12 re-biopsies and observed that 5 specimens displayed mesenchymal traits. Interestingly, some of them also harbored a concomitant second ALK mutation of resistance. Similarly, Gower et al. [2016] described acquired EMT characteristics in tumors harboring ALKTKI resistance. However, reversible models of EMT did not allow to restore sensitivity to ALK inhibitors, suggesting that the EMT process may be associated with but is not required for ALK-TKI resistance. Deciphering further this EMT/ALK mutation status, Fukuda et al. [2019] performed microdissection analyses in a tumor resistant to ALK-rearranged related TKI. This tumor concomitantly harbored an acquired $A L K$ mutation of resistance (L1196M] in epithelial-like tumor area while no additive mutation was found in the mesenchymal-switched tumor area. Taken together, those observations suggest that EMT can be both independent of and additive to mechanisms underlying ALK-TKI-resistant cancers. To investigate the EMT and ALK-TKI resistance relationship, Kogita et al. [2014] established an NSCLC cell line with EML4ALK rearrangement and showed that the hypoxic condition was associated with ALK-TKI resistance by EMTdependent signaling. Beyond molecular mechanisms involving hypoxia-induced actors, e.g., epithelial splicing regulatory protein 1 (ESRP1) [Voena et al., 2016], 3 other EMT-related pathways were involved in ALK-mutant cancers such as proteoglycans, HIF-1, and FoxO signaling, and extracellular matrix-receptor interaction, as re- 
ported by Wei et al. [2018]. Altogether, these observations suggest that resistance to ALK-TKI can be associated with mesenchymal features even though EMT is not the sole driver of resistance.

\section{Others}

Among other targetable oncogenic drivers, some molecular alterations seemed related to EMT. For example, the EMT process has been described as dysregulated in BRAF-mutant cancers, such as primary cutaneous melanoma or papillary thyroid carcinoma [Mitchell et al., 2016]. Possibly due to the low prevalence of $B R A F-\mathrm{mu}$ tant lung cancer $(<1 \%)$, only few works reported on the BRAF/EMT interplay in NSCLC [Urbanska et al., 2020]. With a structural similarity to $A L K$ but lower prevalence, ROS1 alterations are also oncogenic drivers targetable in clinical management [Lin and Shaw, 2017]. Gou et al. [2018] described a mesenchymal polarization in the NSCLC cell line with a CD74-ROS1 G2032R mutation, leading to increased aggressiveness and, interestingly, supporting resistance to ROS1-TKI (crizotinib). Regarding the EMT process, our laboratory observed a more frequent mesenchymal switch in NSCLC cell lines and tumors harboring HER 2 activation, classically related to aggressiveness. Interestingly, anti-HER2 therapies allowed to restore epithelial features and reduce invasiveness $[\mathrm{Da}$ Silva et al., 2020]. Finally, c-MET molecular alterations are also described in a minority of NSCLC, and many preclinical and clinical trials have been designed in lung cancer. However, NSCLC harbor a large heterogeneity in c-MET molecular modification, such as overexpression, amplification, and point mutations, that could explain many controversial results to date [Drilon et al., 2017], although exon-14-skipping mutations seem promising [Pasquini and Giaccone, 2018].

In conclusion, both common and uncommon oncogenic drivers seem intrinsically linked to EMT processes. A large part of studies reported that mesenchymal features are associated with resistance to various drugs. Whether EMT is a consequence of or a prerequisite to drug resistance are 2 nonmutually exclusive possibilities. Elucidation of those phenomena may lead to innovative pharmacological strategies.

\section{EMT and Immune Profile}

Among EMT-induced properties contributing to enhanced metastatic potential, the ability of tumor cells to escape immune surveillance has gained major interest along with the emergence of immunotherapies. Thus, numerous studies report a positive correlation between a mesenchymal switch and the expression of immune checkpoint proteins. As a cornerstone in immunotherapy management, $\mathrm{PD}-(\mathrm{L}) 1$ has been largely explored in NSCLC context. Several in vitro and preclinical studies reported an induction of PD-L1 expression by different EMT pathways and EMT transcription factors, and PDL1/EMT transcription factor coexpression has been reported in human lung cancer specimens [Noman et al., 2017; Asgarova et al., 2018; Li et al., 2018]. This coexpression has actually been observed in many histological types [Alsuliman et al., 2015; Ock et al., 2016; Chen et al., 2017] and largely reported in NSCLC, from metastatic to local and resected lung cancers [Kim et al., 2016; Ancel et al., 2019], and in CTCs [Manjunath et al., 2019]. Other reports studying PD-1 and PD-L1 expression further corroborated this association with EMT phenotypes [Kim et al., 2016; Mak et al., 2016]. Additionally, EMT seems to affect other immune checkpoint systems including CTLA-4 and TIM-3, but also PD-L1/2, PD-1, and B7-H3 that were also found overexpressed, suggesting a wideranging effect of EMT on tumoral immune escape [Lou et al., 2016]. Chae et al. [2018] observed that overexpression of druggable immune checkpoints, such as CTLA-4 and TIM-3 (but not PD-L1 in their study context), is associated with an EMT signature in NSCLC and with a lower infiltration of CD4 T cells. Thus, besides a direct effect on EMT in regulating the expression of immune checkpoint proteins in tumor cells, EMT also acts on immune cell infiltration (discussed later in the paper), which promotes an immunosuppressive TME in the vicinity of EMT-positive areas.

Overall, the EMT process appears as a promising biomarker intrinsically related to tumor aggressiveness in NSCLC. EMT could thus help refining tumor prognosis and clinicians in the choice of pharmacological strategies, especially regarding targetable oncogenic drivers and immunotherapies.

\section{EMT in Clinical Lung Cancer Management}

Aiming at going beyond a descriptive level, we here below report how clinicians could benefit from examining EMT in NSCLC - both in early and metastatic stages.

\section{EMT as a Prognostic Marker of Early Lung Cancer}

As previously mentioned, 5-year survival rates in early-stage NSCLC remain poor, even after complete resection, and relapse is fatal in a large number of cases. Aiming at reducing this burden, adjuvant platinum-based 
regimens are employed, though with limited effects. Many targeted therapies are currently available in lung cancer, but their use is restricted to advanced stages. For example, pre- and/or postoperative anti-PD-(L) 1 cannot be employed although $>50 \%$ tumor specimens harbor PD-L1-positive cells. This highlights a crucial need to further refine tumor characteristics in order to identify patients that could benefit from a personalized strategy such as immune checkpoint inhibitors. Identifying patients with worse outcomes is a key step to this end, and robust prognostic markers are thus needed. Considering the extensive literature bridging EMT to tumor aggressiveness, EMT has been explored, either solely or in combination with other markers, through different approaches that, as we discuss later in the review, still need to be optimized and validated in order to be beneficial in a clinical context. Chikaishi et al. [2011] thus described a noninformative EMT status based on vimentin, $\gamma$-catenin, fibronectin, and E-cadherin expression in 183 resected tumors, which was not able to predict patient outcome. These results could reflect the incorporation of a large number of stage IA tumors, which are known to display a specific, better prognosis, in the study cohort. Examining homogenous and larger cohorts, many other studies reported a positive association between EMT-positive characteristics and poor outcome. The evaluation of the prognostic and predictive value of EMT in early stages of NSCLC (NCT03509779) is being examined in a prospective cohort (TWIST lung). In other studies, higher vimentin expression in tumor cells was proposed as a predictor of metastasis occurrence [Dauphin et al., 2013; Tsoukalas et al., 2017; Aruga et al., 2018; Y. Wang et al., 2019]. In SCCs, vimentin expression failed to establish an independent prognosis, but high S100A expression and lack of intercellular E-cadherin allowed to predict patients at a high risk of recurrence and poor prognosis [Zhang et al., 2013]. Both in ACs and SCCs, reduced membranous staining of E-cadherin and expression of vimentin were shown to be independent predictors of mortality [Che et al., 2015; Aruga et al., 2018; Shao et al., 2019].

Overcoming the clinical challenge to collect tumor biopsies, CTCs in peripheral blood were also explored as a predictor of outcome in early stages of lung cancers. Regarding CTCs, many parameters are faced, such as CTC count, CTC variation, or CTCs employed as liquid biopsy [Cabel et al., 2017; Syrigos et al., 2018]. Moreover, CTCs can be informative through their biomarker expression, and assessing EMT seems promising. Indeed, CTCs with a mesenchymal switch were associated with a poor outcome [Li et al., 2017, p. 4; Liu et al., 2018; de
Miguel-Pérez et al., 2019; Manjunath et al., 2019]. Thus, considering the EMT status in CTCs could allow to enhance the clinical relevance of CTCs in lung cancer management [Wu et al., 2015; Jin et al., 2017; Lowes and Allan, 2018].

To summarize the significance of prognostic markers, studies examining multiple EMT markers are numerous and mainly concordant, supporting the independent capacity of the EMT signature to predict patient outcome. However, it appears crucial to identify some of the most relevant markers to examine their expression in routine practice. In this regard, vimentin and E-cadherin expression seems promising.

\section{EMT in Advanced and Metastatic Lung Cancers}

In addition to promoting local and distant dissemination/recurrence, EMT was proposed by many authors to support resistance to therapies [Dudas et al., 2020]. We here explore the associations of EMT with the therapeutic options currently used in advanced stages of NSCLC, such as chemo/radiotherapies, targeted therapies, and immune checkpoint blocking antibodies.

\section{Resistance to Chemo/Radiotherapy}

Extensive literature today emphasizes a role of EMT in resistance to chemotherapies currently used clinically, such as cisplatin, paclitaxel, gemcitabine, and vinorelbine [Fischer et al., 2015; Toge et al., 2015; Han et al., 2016; Suda et al., 2017; van Staalduinen et al., 2018]. Particularly mesenchymal attributes have been associated with cisplatin resistance, the major first-line chemotherapy in NSCLC. This is supported by numerous in vitro and in vivo data [Chen et al., 2016; Guo et al., 2018; He et al., 2018; Jiang et al., 2019]. Similar findings also support a role of EMT in resistance to docetaxel, a cytotoxic gold standard drug in lung cancer typically used as second-line therapy [Chen et al., 2014; Shen et al., 2014]. Importantly, the majority of these reports emphasized reversible and flexible EMT-mediated resistance processes, offering targeting perspectives. Aiming at circumventing chemotherapy resistance, many interesting approaches are thus being developed to adapt combination treatment protocols and/or to block EMT and sensitize tumor cells to chemotherapy. For instance, examining different protocols of pemetrexed-cisplatin combination treatment on lung cancer cell lines, Tièche et al. [2016] identified a resistant cell subpopulation with EMT and cancer stem cell characteristics emerging in all tested treatment settings. Interestingly, the authors observed that a pretreatment with pemetrexed before the addition of cisplatin reduced the 
emergence of this EMT/cancer stem cell phenotype and significantly enhanced the inhibitory effect of cisplatin on lung cancer cell growth. Another in vitro study reported an EMT-mediated resistance to antifolate pemetrexed chemotherapy and further showed that blocking EMT signaling with the flavonoid kaempferol restored pemetrexed sensitivity [Liang et al., 2015]. Using in vitro drugresistant NSCLC cell models, Kurokawa et al. [2013] observed that acquired cisplatin resistance reduces the sensitivity of cancer cells to a subsequent treatment with gefitinib, an EGFR-TKI. Cisplatin-induced resistance to gefitinib was associated with acquisition of both EMT and induction of AXL, a now well-described EMT-associated tyrosine kinase receptor that may bypass EGFR signaling for survival and proliferation and that has become an attractive therapeutic target.

Regarding radioresistance, some studies have examined the relationships between EMT and ionizing radiation. Radiation was thus shown to induce EMT and enhance motility and invasiveness in various lung cancer cell lines [Jung et al., 2007; Gomez-Casal et al., 2013; Yao et al., 2016; Lu et al., 2018]. As observed for chemoresistance, radioresistance mediated by EMT seemed to be a reversible and targetable process. For instance, Notch1-regulating flavonoid compounds [Rhamnetin and Cirsiliol] were found to inhibit EMT and induce radiosensitization in different NSCLC cell lines [Kang et al., 2013]. $\mathrm{PD}-\mathrm{L} 1$ expression was also reported to be increased along with EMT after ionizing radiation. Down-regulating PD$\mathrm{L} 1$ in radiation-resistant cells was shown to alleviate radiation resistance and to decrease EMT attributes, and radiotherapy combined with anti-PD-L1 antibody synergistically enhanced antitumor immunity in a xenograft mouse model [Gong et al., 2017].

Although limited to preclinical in vitro and in vivo studies, those observations highlight the importance of monitoring EMT to refine sequential therapy, drug combinations, and treatment regimens, and also to identify EMT pathways as potential targets to enhance or restore chemo/radiosensitivity.

\section{EGFR-TKI Resistance}

As mentioned earlier, EMT is involved in primary and acquired resistance to anti-EGFR drugs. Additionally, clinical studies and trials confirmed the potential significance of EMT in anti-EGFR therapies.

Only few clinical reports evaluated EMT in patients with tumors harboring activating EGFR mutations. Those observations associated mesenchymal features with EGFR-TKI resistance [Miyoshi et al., 2015; N. Zhang et al., 2017; Poh et al., 2018]. As there are no validated markers of response to EGFR inhibitors in EGFR wild-type patients, numerous clinical trials assessed EMT as a predictor of response in this molecular context. Thus, Villalobos et al. [2019] examined E-cadherin and vimentin expression in a cohort of 104 advanced and metastatic NSCLC patients who were not selected regarding their EGFR status and treated with erlotinib/bevacizumab or a chemotherapy regimen. It appears that tumors with mesenchymal attributes exhibited increased progression-free survival in the chemotherapy group in comparison to the EGFR-TKI group suggesting better efficacity of standard chemotherapy in comparison to the erlotinib/bevacizumab combination for mesenchymal-like tumors [Villalobos et al., 2019]. Additionally, based on NSCLC cell lines and validated in clinical conditions in the BATTLE- 1 cohort treated with erlotinib (Biomarker-Integrated Approaches of Targeted Therapy for Lung Cancer Elimination), Byers et al. [2013] described an EMT signature able to predict EGFR-TKI resistance. In this (BATTLE-1 NSCLC) cohort, the epithelial EMT signature predicted better disease control in patients receiving erlotinib in comparison to mesenchymal-switched NSCLC. EMT signature was not associated with a different response to other therapies, including platinum drugs, pemetrexed, docetaxel, and paclitaxel. Consequently, the ability to identify tumors that have not undergone EMT may help to select patients who would most likely benefit from EGFR inhibition, e.g., as second-line therapy of patients harboring a wild-type EGFR cancer. Additionally, in vitro studies support that targeting EMT may reverse or prevent acquisition of therapeutic resistance to EGFR inhibitors. This is for instance illustrated in an in vitro study reporting that the reversion of an epithelial phenotype through forced E-cadherin expression in NSCLC cell lines restored sensitivity to the EGFR inhibitor gefitinib [Witta et al., 2006].

In the same line of thought, examining EMT biomarkers resistant to anti-EGFR therapy may also point to EMT-induced alternative pathways that could overcome EGFR signaling for cell survival and growth. This is very well illustrated by numerous studies showing that, as we mentioned earlier, AXL is frequently overexpressed in EGFR inhibitor resistance [Zhang et al., 2012; Singh and Silakari, 2017; Karachaliou et al., 2018; Kim et al., 2019; F. Wang et al., 2019]. AXL is indeed considered a promising target to overcome EGFR resistance. AXL inhibitors have been generated, with some of them assessed in clinical trials such as cabozantinib, a small-size TKI targeting AXL, MET, RET, KIT, and VEGFR2 [Neal et al., 2016; Wakelee 
et al., 2017; Nokihara et al., 2019]. In conclusion, it appears that, in addition to being a biological marker of tumor aggressiveness, EMT signature could be a marker of nonresponse to EGFR-TKIs in lung cancers.

\section{Immune Evasion}

Cancer immunotherapy, including competing antibodies, checkpoint inhibitors, vaccines, and adoptive cell transfer, is based on restoring the immune response towards the tumor. Examining the interplay between EMT and the immune system has been proposed as a promising strategy to improve immunotherapy efficiency [Soundararajan et al., 2019; Horn et al., 2020]. To date, current practice solely relies on blocking antibodies that have already proven to be cornerstone options for patients with lung cancer [Doroshow et al., 2019]. Despite few contradictory results [Cooper et al., 2015; Okita et al., 2017], PD-L1 expression does not seem sufficient to accurately predict response to immune-related drugs [Duma et al., 2019; Xia et al., 2019], and examining potential companion biomarkers both in tumors and CTCs could enhance predictive significance [Kloten et al., 2019]. PD-L1 also remains a poor prognostic indicator of overall survival [Woodard et al., 2016; Takada et al., 2018].

In the PACIFIC study, PD-L1 inhibition by durvalumab showed an improvement in progression-free survival in a narrowly selected cohort of nonmetastatic advanced-stage patients who received chemoradiotherapy pretreatment. Even in doing so, the response rate only reached 28.4\% [Antonia et al., 2018]. This objective response rate (ORR) seems lower and deceiving in comparison to ORRs observed in metastatic stages, showing a real need to refine predictive markers of response. With this in mind, EMT was proposed as a tandem marker with PD-L1 expression to predict resistance to immunotherapy [Jia et al., 2019]. Thus, considering both vimentin and PD-L1 expression in primary tumors [Ancel et al., 2019] or in CTCs [Manjunath et al., 2019] allows to redefine patients with dismal outcome. This subgroup coexpressing high levels of both vimentin and PD-L1 could be associated to worse ORR to immunotherapy.

Furthermore, Funaki et.al. [2017] reported enhanced PD-L1 expression after a platinum-based regimen via TGF- $\beta$-induced EMT in lung cell lines. In addition to the aggressiveness of lung cancer, a strong EMT-PD-L1 correlation could thus explain the efficacy observed for chemotherapies in combination with immunotherapies in NSCLC [Gandhi et al., 2018; Paz-Ares et al., 2018]. Indeed, response improved with durvalumab after chemo- radiation therapy in advanced stages and with the pembrolizumab-chemotherapy combination as first-line therapy in metastatic stages. Considering the major role of EMT in immunosuppression exacerbating resistance to immunotherapies, many reports support the potential advantage of combination therapies to prevent and/or overcome treatment resistance [Soundararajan et al., 2019].

\section{Strategies in Development - Limitations and Perspectives}

In the light of its extensively documented implication in promoting tumor aggressiveness in diverse tumor types and especially in lung cancer, EMT is thus today considered both as a promising companion prognostic/ predictive biomarker and as a target for anticancer therapy. Along these lines, we discuss some propositions and explore the role of the EMT status as a companion biomarker or the effect of EMT inhibition cancer management in different contexts. These propositions are recapitulated in Figure 3.

It is nevertheless important to emphasize that a major limitation to the exploitation of EMT in the clinic resides in the fact that reliable EMT signatures/biomarkers still need to be validated in clinical settings. In order to assess EMT polarization, mRNA expression signature [Rudisch et al., 2015; Chen et al., 2019; Gordian et al., 2019; Thompson et al., 2020] or specific EMT canonical markers are often analyzed. It is important to recognize that tumor cells broadly interplay with stroma, and particularly with stromal mesenchymal cells, including fibroblasts or immune-infiltrative cells that express frequently analyzed EMT markers. The examination of gene expression signature in total mRNA may thus introduce critical biases. Such explorative methods thus need to be further validated with concomitant analysis of tumor-specific marker expression or using other alternative methods such as single-cell sequencing [Karacosta et al., 2019; Ramirez et al., 2020], which is still restricted to the preclinical field.

Fig. 3. Proposal for potential refinements in NSCLC management according to the EMT status and considering that anti-EMT drugs are available. a, b The propositions solely concern cancer contexts in which the EMT status has been interrogated in published studies that are detailed in the main text. These hypothetical management scenarios have been elaborated considering that robust EMT markers/signatures can be validated in clinical practice. The figure thus does not present current therapeutic options.

(For figure see next page.)
Ancel/Dewolf/Deslée/Nawrocky-Raby/ Dalstein/Gilles/Polette 
Therapeutic strategies of non-metastatic NSCLC

Early and advanced resectable stages

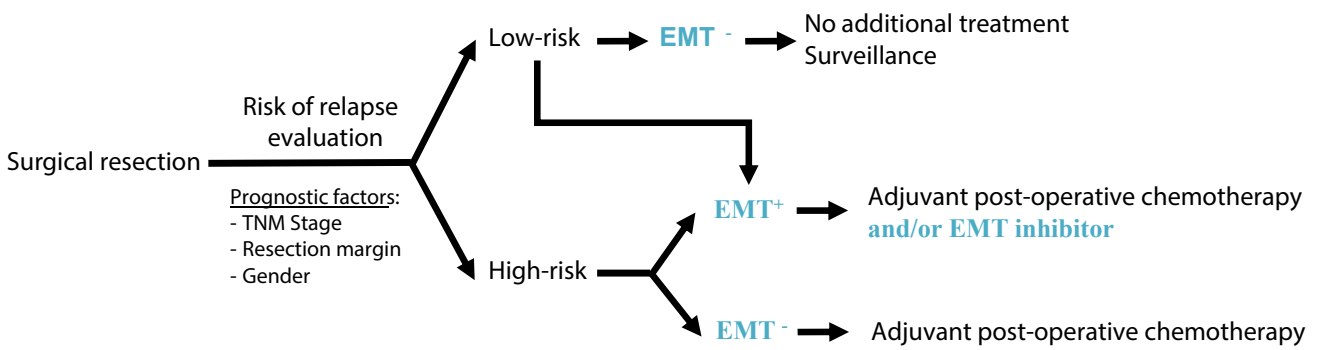

\section{Advanced non-resectable stages}
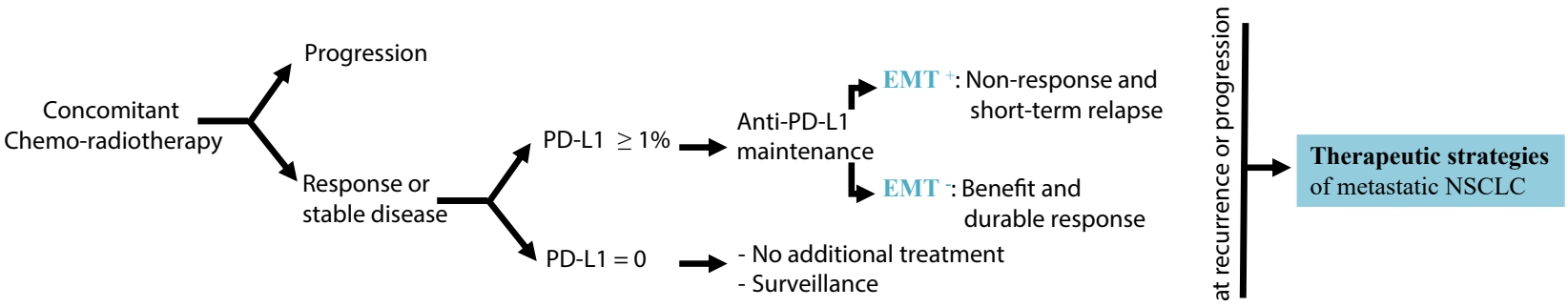

\section{Therapeutic strategies of metastatic NSCLC}

\section{Mutant NSCLC}

KRAS mutated

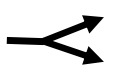

EMT -

$\mathrm{EMT}^{-}$

Therapeutic strategy of non-mutant/ or KRAS inhibitors

Therapeutic strategy of non-mutant
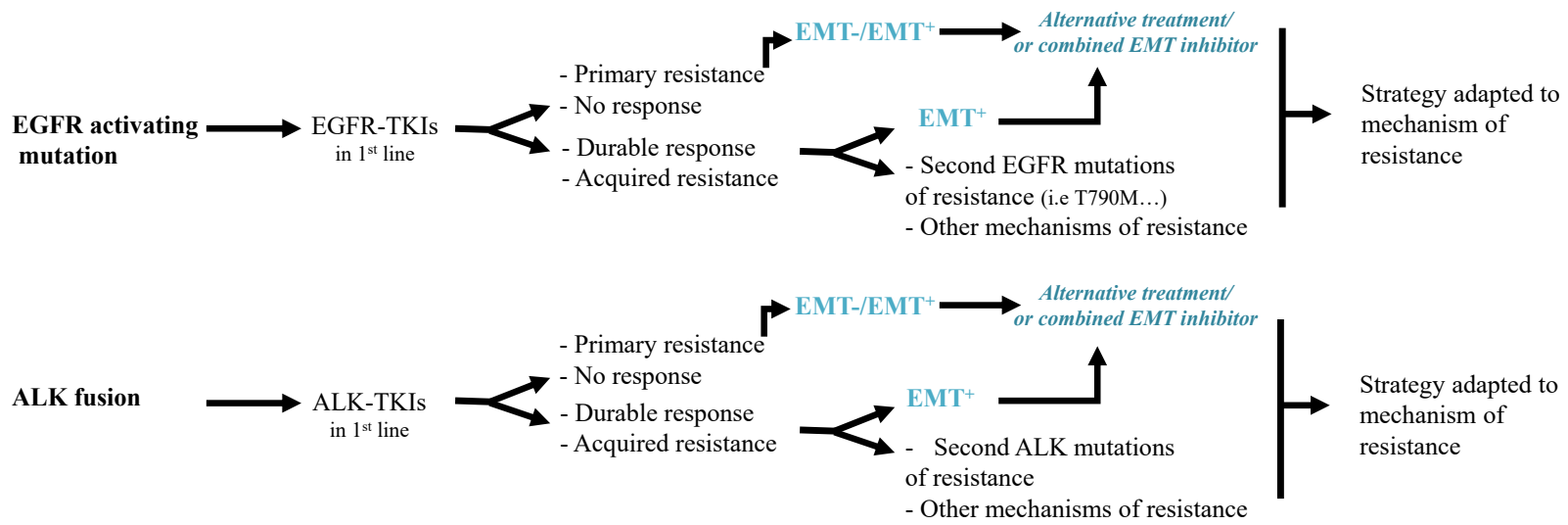

Non-mutant NSCLC

b

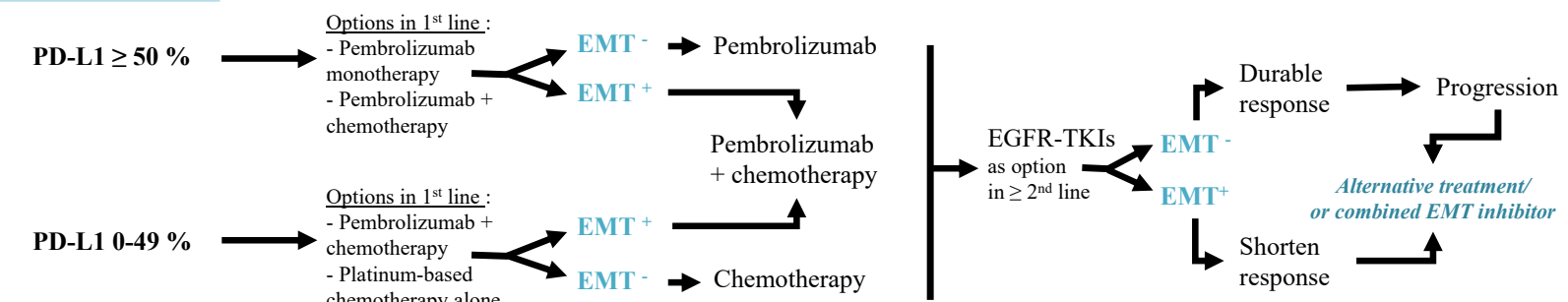


Examining EMT by in situ approaches (immunohistochemistry in combination with epithelial markers such as cytokeratins, in situ hybridization) probably allows a more accurate analysis of EMT-associated gene expression modulations occurring in tumor cells. Nevertheless, determining thresholds and cutoff values to score and define the extend of EMT is also a thorny challenge that needs to be further evaluated in clinical trials, particularly in the context of immunostaining analyses. In this line of thought, to establish a numerical EMT index using selected validated biomarkers is a promising perspective of current EMT research to quantify the extent of EMT in tumors [Fici et al., 2017].

In addition, the tumor material to be analyzed for EMT is also a subject of discussion. In early-stage cancer , pathological examination of whole surgically resected tumors provides information on tumor heterogeneity in its entirety [Neelakantan et al., 2015]. In metastatic disease, EMT characterization based on biopsy samples is limited to fewer tumoral territories mostly in non-pretreated condition. Furthermore, EMT being recognized as a dynamic process associated with tumor invasion and early dissemination, one can hypothesize that metastases would rather contain tumor cells that reverted to more epithelial phenotypes through METs. In order to develop a personalized medicine and to adapt treatments in a realtime manner taking EMT into account, it thus seems pertinent to propose that EMT characterization should be performed on lung primary tumor biopsies and on CTCs issued from timely and repeated liquid biopsies.

Concerning the exploitation of EMT as a therapeutic target, there are no dedicated EMT inhibitors used in the clinic. However, existing drugs impacting RTK (receptor tyrosine kinase) known to be involved in EMT (such as anti-TGF- $\beta$, or Notch and Snail inhibitors) have been used for this purpose in preclinical models [Feng et al., 2020]. Elaborating EMT inhibitors is a very active sector, and many other anti-EMT compounds are being generated, some of which have been tested in NSCLC context [Otsuki et al., 2018]. Most of them are still in preclinical development, and we chose here to illustrate those confronted to clinical phases. RO4929097, a $\gamma$ secretase inhibitor designed to target Notch signaling, has been employed in early phases for ovarian [Diaz-Padilla et al., 2015] and pancreatic [De Jesus-Acosta et al., 2014] cancers with limited results. Phase II trials unfortunately also failed to demonstrate its efficacy on advanced and metastatic NSCLC (NCT01193868) as well as in recurrent or refractory NSCLC (NCT01070927) alone or in combination with erlotinib (NCT01193881). To date, drug pro- duction has been stopped. A well-designed and randomized phase II study of 132 patients evaluated the outcome of erlotinib combined or not to entinostat (isoform selective histone deacetylase inhibitor) as a potential inhibitor of EMT. Erlotinib combined with entinostat exhibited a safety profile but did not improve progression-free survival based on a 4-month follow-up in the study population. Interestingly, overall survival was longer in patients with high E-cadherin levels assessed at the time of diagnosis, demonstrating the need to identify predictive biomarkers to improve patient stratification [Witta et al., 2012]. With the aim to identify biomarkers indicating response to EGFR-TKIs in NSCLC patients, Reckamp et al. [2008] originally assessed EMT markers in serum samples from 22 patients. Decreased soluble E-cadherin and MMP-9 serum levels between baseline and the first follow-up were correlated with better response to the erlotinib-celecoxib combination. However, this combination did not seem to improve outcome in an unselected population in a phase II trial [Reckamp et al., 2015]. TLY3039478, which was also designed against Notch, has been tested in a phase I trial. Eight patients with advanced NSCLC were recruited, demonstrating safety with efficacy based on metabolic response or tumor necrosis [Massard et al., 2018]. A further clinical trial based on this drug is still recruiting (NCT02836600). Innovative strategies such as si-mi-RNAs could also represent an interesting approach in solid tumors [Naghizadeh et al., 2019], although their vectorization process is still insufficiently developed to date [Wang et al., 2014].

Targeting EMT in NSCLC could thus be beneficial alone but more probably in combination, specifically with chemotherapies to prevent and/or overcome resistance to actual treatments. Combining anti-EMT molecules with chemotherapy may also conceptually override a suspected implication of MET in metastatic outgrowth. Combination of anti-EMTs with other targeted therapies may also be beneficial. Additionally, the redundancy of EMT activation pathways (Fig. 2) also constitutes a clear challenge in targeting EMTs [Zoni et al., 2015; Yin et al., 2019] and pleads in favor of multitarget TKI approaches that are being examined [de Jonge et al., 2019; Hellerstedt et al., 2019; Wheatley-Price et al., 2019]. Multiple therapeutics against EMT-activating pathways (e.g., TGF $\beta$, FAK, FGFR, or PDGFR) have been tested with no convincing effects [Giaccone et al., 2015; Paik et al., 2017; Han et al., 2018; Gerber et al., 2020], although research is still ongoing with FGFR [SenthilKumar et al., 2020] or FAK inhibitors [Mak et al., 2019]. Among EMT-associated targetable receptor pathways, AXL seems currently
12

Cells Tissues Organs DOI: $10.1159 / 000510103$
Ancel/Dewolf/Deslée/Nawrocky-Raby/ Dalstein/Gilles/Polette 
one of the most promising [C. Zhu et al., 2019]. Accordingly, AXL small molecule inhibitors are currently being tested as monotherapy or in combination with chemotherapy or anti-EGFR therapy in clinical trials [Levin et al., 2016; Kim et al., 2020].

On the other hand, the high prevalence of PD-L1 expression in tumors with mesenchymal attributes and accumulating data evidencing resistance to immune checkpoint inhibitors suggest that the selection/management of patients that may benefit from anti-PD-L1 therapies may be refined. Thus, among patients with high PD-L1 expression, a mesenchymal switch would predict resistance to immunotherapies in comparison to tumors with an epithelial-like phenotype. As a hypothesis, patients with NSCLC harboring EMT+/PD-L1+ markers could thus benefit from a combination of immunotherapy with chemotherapy. Synergistic effects of TGF- $\beta$ inhibition combined with PD-L1 blockade are also explored [Sow et al., 2019; Lind et al., 2020].

\section{Conclusion}

Numerous data emphasize a narrow relationship between EMT and lung cancer in early-advanced and metastatic stages. Examining EMT parameters as a routine biomarker is foreseen to improve personalized lung cancer management. For early-resected lung cancer, the detection of EMT traits could help identifying patients with worse outcomes and guide clinicians towards an adaptation of clinical surveillance and adjuvant strategies. For conventional therapies, immunotherapies, and oncogen- ic driver-targeted therapies, EMT may appear as a predictive factor and/or marker of resistance and could steer clinicians to an alternative therapeutic option. Specific EMT actors may also represent promising, new therapeutic targets to be used in combination therapy. A better characterization of most relevant EMT actors to be considered for specific purposes seems crucial and will undoubtedly facilitate and speed up the implementation of EMT consideration in clinical practice.

\section{Acknowledgment}

The research effort associated with this review was funded in part by the Partenariat Hubert Curien-Tournesol. C.G. is a Senior Associate Researcher from FRS-FNRS (Belgium).

\section{Conflict of Interest Statement}

The authors declare that they have no conflicts of interest.

\section{Funding Sources}

This research received no external funding.

\section{Author Contributions}

All authors, J.A., M.D., G.D., B.N.-R., V.D., M.P. and C.G., participated in manuscript preparation and revision. All authors read and approved the final manuscript.

\section{References}

Alix-Panabières C, Mader S, Pantel K. Epithelialmesenchymal plasticity in circulating tumor cells. J Mol Med (Berl). 2017 Feb;95(2):133-42.

Alsuliman A, Colak D, Al-Harazi O, Fitwi H, Tulbah A, Al-Tweigeri T, et al. Bidirectional crosstalk between PD-L1 expression and epithelial to mesenchymal transition: significance in claudin-low breast cancer cells. Mol Cancer. 2015 Aug;14(1):149.

Ancel J, Birembaut P, Dewolf M, Durlach A, Nawrocki-Raby B, Dalstein V, et al. Programmed Death-Ligand 1 and Vimentin: A Tandem Marker as Prognostic Factor in NSCLC. Cancers (Basel). 2019 Sep;11(10):E1411.

Antonia SJ, Villegas A, Daniel D, Vicente D, Murakami S, Hui R, et al.; PACIFIC Investigators. Overall Survival with Durvalumab after Chemoradiotherapy in Stage III NSCLC. N Engl J Med. 2018 Dec;379(24):2342-50.
Antony J, Huang RY. AXL-Driven EMT State as a Targetable Conduit in Cancer. Cancer Res. 2017 Jul;77(14):3725-32.

Aran V, Omerovic J. Current Approaches in NSCLC Targeting K-RAS and EGFR. Int J Mol Sci. 2019 Nov;20(22):E5701.

Arbour KC, Riely GJ. Systemic Therapy for Locally Advanced and Metastatic Non-Small Cell Lung Cancer: A Review. JAMA. 2019 Aug;322(8):764-74.

Arner EN, Du W, Brekken RA. Behind the Wheel of Epithelial Plasticity in KRAS-Driven Cancers. Front Oncol. 2019 Oct; 9:1049.

Aruga N, Kijima H, Masuda R, Onozawa H, Yoshizawa T, Tanaka M, et al. Epithelial-mesenchymal Transition (EMT) is Correlated with Patient's Prognosis of Lung Squamous Cell Carcinoma. Tokai J Exp Clin Med. 2018 Apr; 43(1):5-13.
Asgarova A, Asgarov K, Godet $\mathrm{Y}$, Peixoto $\mathrm{P}$, Nadaradjane A, Boyer-Guittaut M, et al. PDL1 expression is regulated by both DNA methylation and NF-kB during EMT signaling in non-small cell lung carcinoma. OncoImmunology. 2018 Feb;7(5):e1423170.

Bhatia S, Wang P, Toh A, Thompson EW. New Insights into the Role of Phenotypic Plasticity and EMT in Driving Cancer Progression. Front Mol Biosci. 2020 Apr;7:71.

Bian T, Zheng L, Jiang D, Liu J, Zhang J, Feng J, et al. Overexpression of fibronectin type III domain containing $3 \mathrm{~B}$ is correlated with epithelial-mesenchymal transition and predicts poor prognosis in lung adenocarcinoma. Exp Ther Med. 2019 May;17(5):3317-26. 
Bray F, Ferlay J, Soerjomataram I, Siegel RL, Torre LA, Jemal A. Global cancer statistics 2018: GLOBOCAN estimates of incidence and mortality worldwide for 36 cancers in 185 countries. CA Cancer J Clin. 2018 Nov;68(6): 394-424.

Broderick SR. Adjuvant and Neoadjuvant Immunotherapy in Non-small Cell Lung Cancer. Thorac Surg Clin. 2020 May;30(2):215-20.

Bronte G, Bravaccini S, Bronte E, Burgio MA, Rolfo C, Delmonte A, et al. Epithelial-to-mesenchymal transition in the context of epidermal growth factor receptor inhibition in nonsmall-cell lung cancer. Biol Rev Camb Philos Soc. 2018 Nov;93(4):1735-46.

Byers LA, Diao L, Wang J, Saintigny P, Girard L, Peyton M, et al. An epithelial-mesenchymal transition gene signature predicts resistance to EGFR and PI3K inhibitors and identifies Axl as a therapeutic target for overcoming EGFR inhibitor resistance. Clin Cancer Res. 2013 Jan;19(1):279-90.

Cabel L, Proudhon C, Gortais H, Loirat D, Coussy F, Pierga JY, et al. Circulating tumor cells: clinical validity and utility. Int $\mathrm{J}$ Clin Oncol. 2017 Jun;22(3):421-30.

Carlisle JW, Ramalingam SS. Role of osimertinib in the treatment of EGFR-mutation positive non-small-cell lung cancer. Future Oncol. 2019 Mar;15(8):805-16.

Castellanos E, Feld E, Horn L. Driven by Mutations: The Predictive Value of Mutation Subtype in EGFR-Mutated Non-Small Cell Lung Cancer. J Thorac Oncol. 2017 Apr;12(4):612-23.

Chae YK, Chang S, Ko T, Anker J, Agte S, Iams $\mathrm{W}$, et al. Epithelial-mesenchymal transition (EMT) signature is inversely associated with T-cell infiltration in non-small cell lung cancer (NSCLC). Sci Rep. 2018 Feb;8(1):2918.

Che J, Yang Y, Xiao J, Zhao P, Yan B, Dong S, et al. Decreased expression of claudin-3 is associated with a poor prognosis and EMT in completely resected squamous cell lung carcinoma. Tumour Biol. 2015 Aug;36(8):6559-68.

Chen D, Huang J, Zhang K, Pan B, Chen J, De W, et al. MicroRNA-451 induces epithelial-mesenchymal transition in docetaxel-resistant lung adenocarcinoma cells by targeting proto-oncogene c-Myc. Eur J Cancer. 2014 Nov; 50(17):3050-67.

Chen L, Xiong Y, Li J, Zheng X, Zhou Q, Turner A, et al. PD-L1 Expression Promotes Epithelial to Mesenchymal Transition in Human Esophageal Cancer. Cell Physiol Biochem. 2017;42(6):2267-80.

Chen QY, Jiao DM, Wang J, Hu H, Tang X, Chen J, et al. miR-206 regulates cisplatin resistance and EMT in human lung adenocarcinoma cells partly by targeting MET. Oncotarget. 2016 Apr;7(17):24510-26.

Chen YL, Zhang Y, Wang J, Chen N, Fang W, Zhong J, et al. A 17 gene panel for non-smallcell lung cancer prognosis identified through integrative epigenomic-transcriptomic analyses of hypoxia-induced epithelial-mesenchymal transition. Mol Oncol. 2019 Jul;13(7): 1490-502.
Chikaishi Y, Uramoto H, Tanaka F. The EMT status in the primary tumor does not predict postoperative recurrence or disease-free survival in lung adenocarcinoma. Anticancer Res. 2011 Dec;31(12):4451-6.

Ciuleanu T, Stelmakh L, Cicenas S, Miliauskas S, Grigorescu AC, Hillenbach C, et al. Efficacy and safety of erlotinib versus chemotherapy in second-line treatment of patients with advanced, non-small-cell lung cancer with poor prognosis (TITAN): a randomised multicentre, open-label, phase 3 study. Lancet Oncol. 2012 Mar; 13(3):300-8.

Cooper WA, Tran T, Vilain RE, Madore J, Selinger CI, Kohonen-Corish M, et al. PD-L1 expression is a favorable prognostic factor in early stage non-small cell carcinoma. Lung Cancer. 2015 Aug;89(2):181-8.

Cortot AB, Repellin CE, Shimamura T, Capelletti $\mathrm{M}$, Zejnullahu K, Ercan D, et al. Resistance to irreversible EGF receptor tyrosine kinase inhibitors through a multistep mechanism involving the IGF1R pathway. Cancer Res. 2013 Jan;73(2):834-43.

Da Silva J, Jouida A, Ancel J, Dalstein V, Routhier J, Delepine G, et al. FHITlow / pHER2high signature in non-small cell lung cancer is predictive of anti-HER2 molecule efficacy. J Pathol. 2020 Jun;251(2):187-99.

Dauphin M, Barbe C, Lemaire S, Nawrocki-Raby B, Lagonotte E, Delepine G, et al. Vimentin expression predicts the occurrence of metastases in non small cell lung carcinomas. Lung Cancer. 2013 Jul;81(1):117-22.

De Jesus-Acosta A, Laheru D, Maitra A, Arcaroli J, Rudek MA, Dasari A, et al. A phase II study of the gamma secretase inhibitor RO4929097 in patients with previously treated metastatic pancreatic adenocarcinoma. Invest New Drugs. 2014 Aug;32(4):739-45.

de Jonge MJ, Steeghs N, Lolkema MP, Hotte SJ, Hirte HW, van der Biessen DA, et al. Phase I Study of BI 853520, an Inhibitor of Focal Adhesion Kinase, in Patients with Advanced or Metastatic Nonhematologic Malignancies. Target Oncol. 2019 Feb;14(1):43-55.

De Matteis S, Canale M, Verlicchi A, Bronte G, Delmonte A, Crinò L, et al. Advances in Molecular Mechanisms and Immunotherapy Involving the Immune Cell-Promoted Epithelial-to-Mesenchymal Transition in Lung Cancer. J Oncol. 2019 Aug;2019:7475364.

de Miguel-Pérez D, Bayarri-Lara CI, Ortega FG, Russo A, Moyano Rodriguez MJ, Alvarez-Cubero MJ, et al. Post-Surgery Circulating Tumor Cells and AXL Overexpression as New Poor Prognostic Biomarkers in Resected Lung Adenocarcinoma. Cancers (Basel). 2019 Nov;11(11):E1750.

Del Re M, Crucitta S, Gianfilippo G, Passaro A, Petrini I, Restante G, et al. Understanding the Mechanisms of Resistance in EGFR-Positive NSCLC: From Tissue to Liquid Biopsy to Guide Treatment Strategy. Int J Mol Sci. 2019 Aug;20(16):E3951.

Diaz-Padilla I, Wilson MK, Clarke BA, Hirte HW, Welch SA, Mackay HJ, et al. A phase II study of single-agent RO4929097, a gamma-secretase inhibitor of Notch signaling, in patients with recurrent platinum-resistant epithelial ovarian cancer: A study of the Princess Margaret, Chicago and California phase II consortia. Gynecol Oncol. 2015 May;137(2):21622.

Dominguez C, David JM, Palena C. Epithelialmesenchymal transition and inflammation at the site of the primary tumor. Semin Cancer Biol. 2017 Dec;47:177-84.

Dongre A, Weinberg RA. New insights into the mechanisms of epithelial-mesenchymal transition and implications for cancer. Nat Rev Mol Cell Biol. 2019 Feb;20(2):69-84.

Doroshow DB, Sanmamed MF, Hastings K, Politi K, Rimm DL, Chen L, et al. Immunotherapy in Non-Small Cell Lung Cancer: Facts and Hopes. Clin Cancer Res. 2019 Aug;25(15): 4592-602.

Drilon A, Cappuzzo F, Ou SI, Camidge DR. Targeting MET in Lung Cancer: Will Expectations Finally Be MET? J Thorac Oncol. 2017 Jan;12(1):15-26.

Du X, Shao Y, Qin HF, Tai YH, Gao HJ. ALKrearrangement in non-small-cell lung cancer (NSCLC). Thorac Cancer. 2018 Apr;9(4): 423-30.

Dudas J, Ladanyi A, Ingruber J, Steinbichler TB, Riechelmann H. Epithelial to Mesenchymal Transition: A Mechanism that Fuels Cancer Radio/Chemoresistance. Cells. 2020 Feb; 9(2):E428.

Duma N, Santana-Davila R, Molina JR. NonSmall Cell Lung Cancer: Epidemiology, Screening, Diagnosis, and Treatment. Mayo Clin Proc. 2019 Aug;94(8):1623-40.

Feng YL, Chen DQ, Vaziri ND, Guo Y, Zhao YY. Small molecule inhibitors of epithelial-mesenchymal transition for the treatment of cancer and fibrosis. Med Res Rev. 2020 Jan;40(1): 54-78.

Fici P, Gallerani G, Morel AP, Mercatali L, Ibrahim T, Scarpi E, et al. Splicing factor ratio as an index of epithelial-mesenchymal transition and tumor aggressiveness in breast cancer. Oncotarget. 2017 Jan;8(2):2423-36.

Fischer KR, Durrans A, Lee S, Sheng J, Li F, Wong ST, et al. Epithelial-to-mesenchymal transition is not required for lung metastasis but contributes to chemoresistance. Nature. 2015 Nov;527(7579):472-6.

Foster JG, Wong SC, Sharp TV. The hypoxic tumor microenvironment: driving the tumorigenesis of non-small-cell lung cancer. Future Oncol. 2014 Dec;10(16):2659-74.

Francart ME, Lambert J, Vanwynsberghe AM, Thompson EW, Bourcy M, Polette M, et al. Epithelial-mesenchymal plasticity and circulating tumor cells: travel companions to metastases. Dev Dyn. 2018 Mar;247(3):432-50.

Fukuda K, Takeuchi S, Arai S, Katayama R, Nanjo S, Tanimoto A, et al. Epithelial-to-Mesenchymal Transition Is a Mechanism of ALK Inhibitor Resistance in Lung Cancer Independent of ALK Mutation Status. Cancer Res. 2019 Apr;79(7):1658-70. 
Funaki S, Shintani Y, Kawamura T, Kanzaki R, Minami M, Okumura M. Chemotherapy enhances programmed cell death 1 /ligand $1 \mathrm{ex}-$ pression via TGF- $\beta$ induced epithelial mesenchymal transition in non-small cell lung cancer. Oncol Rep. 2017 Oct;38(4):2277-84.

Gainor JF, Dardaei L, Yoda S, Friboulet L, Leshchiner I, Katayama R, et al. Molecular Mechanisms of Resistance to First- and SecondGeneration ALK Inhibitors in ALK-Rearranged Lung Cancer. Cancer Discov. 2016 Oct;6(10):1118-33.

Galván JA, Astudillo A, Vallina A, Crespo G, Folgueras MV, González MV. Prognostic and diagnostic value of epithelial to mesenchymal transition markers in pulmonary neuroendocrine tumors. BMC Cancer. 2014 Nov;14(1): 855.

Gandhi L, Rodríguez-Abreu D, Gadgeel S, Esteban E, Felip E, De Angelis F, et al.; KEYNOTE-189 Investigators. Pembrolizumab plus Chemotherapy in Metastatic Non-SmallCell Lung Cancer. N Engl J Med. 2018 May; 378(22):2078-92.

Genna A, Vanwynsberghe AM, Villard AV, Pottier C, Ancel J, Polette M, et al. EMT-Associated Heterogeneity in Circulating Tumor Cells: Sticky Friends on the Road to Metastasis. Cancers (Basel). 2020 Jun;12(6):E1632.

Gerber DE, Camidge DR, Morgensztern D, Cetnar J, Kelly RJ, Ramalingam SS, et al. Phase 2 study of the focal adhesion kinase inhibitor defactinib (VS-6063) in previously treated advanced KRAS mutant non-small cell lung cancer. Lung Cancer. 2020 Jan;139:60-7.

Giaccone G, Bazhenova LA, Nemunaitis J, Tan M, Juhász E, Ramlau R, et al. A phase III study of belagenpumatucel-L, an allogeneic tumour cell vaccine, as maintenance therapy for nonsmall cell lung cancer. Eur J Cancer. 2015 Nov;51(16):2321-9.

Gibbons DL, Lin W, Creighton CJ, Rizvi ZH, Gregory PA, Goodall GJ, et al. Contextual extracellular cues promote tumor cell EMT and metastasis by regulating miR-200 family expression. Genes Dev. 2009 Sep;23(18):214051.

Goldstraw P, Chansky K, Crowley J, Rami-Porta R, Asamura H, Eberhardt WE, et al.; International Association for the Study of Lung Cancer Staging and Prognostic Factors Committee Advisory Boards and Participating Institutions. The IASLC Lung Cancer Staging Project: Proposals for Revision of the TNM Stage Groupings in the Forthcoming (Eighth) Edition of the TNM Classification for Lung Cancer. J Thorac Oncol. 2016 Jan;11(1):3951

Gomez-Casal R, Bhattacharya C, Ganesh N, Bailey L, Basse P, Gibson M, et al. Non-small cell lung cancer cells survived ionizing radiation treatment display cancer stem cell and epithelial-mesenchymal transition phenotypes. Mol Cancer. 2013 Aug;12(1):94.

Gong X, Li X, Jiang T, Xie H, Zhu Z, Zhou F, et al. Combined Radiotherapy and Anti-PD-L1 Antibody Synergistically Enhances Antitu- mor Effect in Non-Small Cell Lung Cancer. J Thorac Oncol. 2017 Jul;12(7):1085-97.

Goossens S, Vandamme N, Van Vlierberghe P, Berx G. EMT transcription factors in cancer development re-evaluated: beyond EMT and MET. Biochim Biophys Acta Rev Cancer. 2017 Dec;1868(2):584-91.

Gordian E, Welsh EA, Gimbrone N, Siegel EM, Shibata D, Creelan BC, et al. Transforming growth factor $\beta$-induced epithelial-to-mesenchymal signature predicts metastasis-free survival in non-small cell lung cancer. Oncotarget. 2019 Jan;10(8):810-24.

Gou W, Zhou X, Liu Z, Wang L, Shen J, Xu X, et al. CD74-ROS1 G2032R mutation transcriptionally up-regulates Twist 1 in non-small cell lung cancer cells leading to increased migration, invasion, and resistance to crizotinib. Cancer Lett. 2018 May;422:19-28.

Gower A, Hsu W-H, Hsu S-T, Wang Y, Giaccone G. EMT is associated with, but does not drive resistance to ALK inhibitors among EML4ALK non-small cell lung cancer. Mol Oncol. 2016;10:601-9.

Guo J, Jin D, Wu Y, Yang L, Du J, Gong K, et al. The miR 495-UBE2C-ABCG2/ERCC1 axis reverses cisplatin resistance by downregulating drug resistance genes in cisplatin-resistant non-small cell lung cancer cells. EBioMedicine. 2018 Sep;35:204-21.

Han B, Li K, Zhao Y, Li B, Cheng Y, Zhou J, et al. Anlotinib as a third-line therapy in patients with refractory advanced non-small-cell lung cancer: a multicentre, randomised phase II trial (ALTER0302). Br J Cancer. 2018 Mar; 118(5):654-61.

Han ML, Zhao YF, Tan CH, Xiong YJ, Wang WJ, $\mathrm{Wu} \mathrm{F}$, et al. Cathepsin L upregulation-induced EMT phenotype is associated with the acquisition of cisplatin or paclitaxel resistance in A549 cells. Acta Pharmacol Sin. 2016 Dec; 37(12):1606-22.

He Y, Xie H, Yu P, Jiang S, Wei L. FOXC2 promotes epithelial-mesenchymal transition and cisplatin resistance of non-small cell lung cancer cells. Cancer Chemother Pharmacol. 2018 Dec;82(6):1049-59.

Hellerstedt BA, Vogelzang NJ, Kluger HM, Yasenchak CA, Aftab DT, Ramies DA, et al. Results of a Phase II Placebo-controlled Randomized Discontinuation Trial of Cabozantinib in Patients with Non-small-cell Lung Carcinoma. Clin Lung Cancer. 2019 Mar; 20(2):74-81.e1.

Hida T, Nokihara H, Kondo M, Kim YH, Azuma $\mathrm{K}$, Seto $\mathrm{T}$, et al. Alectinib versus crizotinib in patients with ALK-positive non-small-cell lung cancer (J-ALEX): an open-label, randomised phase 3 trial. Lancet. 2017 Jul; 390(10089):29-39.

Hirsch FR, Scagliotti GV, Mulshine JL, Kwon R, Curran WJ Jr, Wu YL, et al. Lung cancer: current therapies and new targeted treatments. Lancet. 2017 Jan;389(10066):299-311.

Horn LA, Fousek K, Palena C. Tumor Plasticity and Resistance to Immunotherapy. Trends Cancer. 2020 May;6(5):432-41.
Hung JJ, Yang MH, Hsu HS, Hsu WH, Liu JS, Wu KJ. Prognostic significance of hypoxia-inducible factor-1alpha, TWIST1 and Snail expression in resectable non-small cell lung cancer. Thorax. 2009 Dec;64(12):1082-9.

Ito T, Kudoh S, Ichimura T, Fujino K, Hassan WA, Udaka N. Small cell lung cancer, an epithelial to mesenchymal transition (EMT)-like cancer: significance of inactive Notch signaling and expression of achaete-scute complex homologue 1. Hum Cell. 2017 Jan;30(1):1-10.

Jia D, Li X, Bocci F, Tripathi S, Deng Y, Jolly MK, et al. Quantifying cancer epithelial-mesenchymal plasticity and its association with stemness and immune response. J Clin Med. 2019 May;8(5):725.

Jiang GB, Fang HY, Tao DY, Chen XP, Cao FL. COX-2 potentiates cisplatin resistance of non-small cell lung cancer cells by promoting EMT in an AKT signaling pathway-dependent manner. Eur Rev Med Pharmacol Sci. 2019 May;23(9):3838-46.

Jiang YN, Ni XY, Yan HQ, Shi L, Lu NN, Wang YN, et al. Interleukin 6-triggered ataxia-telangiectasia mutated kinase activation facilitates epithelial-to-mesenchymal transition in lung cancer by upregulating vimentin expression. Exp Cell Res. 2019 Aug;381(2):165-71.

Jin XR, Zhu LY, Qian K, Feng YG, Zhou JH, Wang $\mathrm{RW}$, et al. Circulating tumor cells in early stage lung adenocarcinoma: a case series report and literature review. Oncotarget. 2017 Apr;8(14):23130-41.

Jung JW, Hwang SY, Hwang JS, Oh ES, Park S, Han IO. Ionising radiation induces changes associated with epithelial-mesenchymal transdifferentiation and increased cell motility of A549 lung epithelial cells. Eur J Cancer. 2007 May;43(7):1214-24.

Kang J, Kim E, Kim W, Seong KM, Youn H, Kim JW, et al. Rhamnetin and cirsiliol induce radiosensitization and inhibition of epithelialmesenchymal transition (EMT) by miR-34amediated suppression of Notch-1 expression in non-small cell lung cancer cell lines. J Biol Chem. 2013 Sep;288(38):27343-57.

Karachaliou N, Chaib I, Cardona AF, Berenguer J, Bracht JW, Yang J, et al. Common co-activation of AXL and CDCP1 in EGFR-mutation-positive Non-smallcell Lung Cancer Associated With Poor Prognosis. EBioMedicine. 2018 Mar;29:112-27.

Karacosta LG, Anchang B, Ignatiadis N, Kimmey SC, Benson JA, Shrager JB, et al. Mapping lung cancer epithelial-mesenchymal transition states and trajectories with single-cell resolution. Nat Commun. 2019 Dec;10(1):5587.

Katayama R. Drug resistance in anaplastic lymphoma kinase-rearranged lung cancer. Cancer Sci. 2018 Mar;109(3):572-80.

Katoh M, Nakagama H. FGF receptors: cancer biology and therapeutics. Med Res Rev. 2014 Mar;34(2):280-300.

Kidd ME, Shumaker DK, Ridge KM. The role of vimentin intermediate filaments in the progression of lung cancer. Am J Respir Cell Mol Biol. 2014 Jan;50(1):1-6. 
Kim D, Bach DH, Fan YH, Luu TT, Hong JY, Park $\mathrm{HJ}$, et al. AXL degradation in combination with EGFR-TKI can delay and overcome acquired resistance in human non-small cell lung cancer cells. Cell Death Dis. 2019 May; 10(5):361.

Kim NY, Suh YA, Kim S, Lee C. Bufalin downregulates Axl expression to inhibit cell proliferation and induce apoptosis in non-smallcell lung cancer cells. Biosci Rep. 2020 Apr; 40(4):BSR20193959.

Kim S, Koh J, Kim MY, Kwon D, Go H, Kim YA, et al. PD-L1 expression is associated with epithelial-to-mesenchymal transition in adenocarcinoma of the lung. Hum Pathol. 2016 Dec;58:7-14

Kloten V, Lampignano R, Krahn T, Schlange T. Circulating Tumor Cell PD-L1 Expression as Biomarker for Therapeutic Efficacy of Immune Checkpoint Inhibition in NSCLC. Cells. 2019 Aug;8(8):E809.

Kobayashi S, Boggon TJ, Dayaram T, Jänne PA, Kocher O, Meyerson M, et al. EGFR mutation and resistance of non-small-cell lung cancer to gefitinib. N Engl J Med. 2005 Feb;352(8): 786-92.

Kogita A, Togashi Y, Hayashi H, Sogabe S, Terashima M, De Velasco MA, et al. Hypoxia induces resistance to ALK inhibitors in the H3122 non-small cell lung cancer cell line with an ALK rearrangement via epithelialmesenchymal transition. Int J Oncol. 2014 Oct;45(4):1430-6.

Kondo M, Ogino H, Ogawa H, Afroj T, Toyoda Y, Sakaguchi S, et al. A case of pulmonary pleomorphic carcinoma with malignant phenotypes induced by ZEB1-associated epithelial-mesenchymal transition. Respir Med Case Rep. 2018 Aug;25:119-21.

Kris MG, Faivre-Finn C, Kordbacheh T, Chaft J, Luo J, Tsao A, et al. Making Checkpoint Inhibitors Part of Treatment of Patients With Locally Advanced Lung Cancers: The Time Is Now. Am Soc Clin Oncol Educ Book. 2020 Mar; 40:1-12.

Kurokawa M, Ise N, Omi K, Goishi K, Higashiyama $S$. Cisplatin influences acquisition of resistance to molecular-targeted agents through epithelial-mesenchymal transition-like changes. Cancer Sci. 2013 Jul;104(7):904-11.

Levin PA, Brekken RA, Byers LA, Heymach JV, Gerber DE. Axl Receptor Axis: A New Therapeutic Target in Lung Cancer. J Thorac Oncol. 2016 Aug;11(8):1357-62.

Li F, Zhu T, Yue Y, Zhu X, Wang J, Liang L. Preliminary mechanisms of regulating $\mathrm{PD}$-L1 expression in non-small cell lung cancer during the EMT process. Oncol Rep. 2018 Aug;40(2): 775-82.

Li G, Wang Y, Tan G. The construction of EpCAM/vimentin-PLGA/lipid immunomagnetic microspheres and the isolation of circulating tumor cells from lung cancer. Int $J$ Clin Exp Pathol. 2018 Dec;11(12):5561-70.

Li S, Chen Q, Li H, Wu Y, Feng J, Yan Y. Mesenchymal circulating tumor cells (CTCs) and OCT4 mRNA expression in CTCs for prog- nosis prediction in patients with non-smallcell lung cancer. Clin Transl Oncol. 2017 Sep; 19(9):1147-53.

Li Y, Wu S, Bai F. Molecular characterization of circulating tumor cells-from bench to bedside. Semin Cell Dev Biol. 2018 Mar;75:8897.

Liang SQ, Marti TM, Dorn P, Froment L, Hall SR, Berezowska S, et al. Blocking the epithelialto-mesenchymal transition pathway abrogates resistance to anti-folate chemotherapy in lung cancer. Cell Death Dis. 2015 Jul; 6(7):e1824.

Liao ZJ, Guo YH, Zhao Z, Yao JT, Xu R, Nan KJ. Gemcitabine inhibits the micrometastasis of non-small cell lung cancer by targeting the EpCAM-positive circulating tumor cells via the HGF/cMET pathway. Int J Oncol. 2014 Aug;45(2):651-8.

Lim SM, Syn NL, Cho BC, Soo RA. Acquired resistance to EGFR targeted therapy in nonsmall cell lung cancer: mechanisms and therapeutic strategies. Cancer Treat Rev. 2018 Apr; 65:1-10.

Lin JJ, Shaw AT. Recent Advances in Targeting ROS1 in Lung Cancer. J Thorac Oncol. 2017 Nov; 12(11):1611-25.

Lind H, Gameiro SR, Jochems C, Donahue RN, Strauss J, Gulley JL, et al. Dual targeting of TGF- $\beta$ and PD-L1 via a bifunctional anti-PDL1/TGF- $\beta$ RII agent: status of preclinical and clinical advances. J Immunother Cancer. 2020 Feb;8(1):e000433.

Lindsay CR, Faugeroux V, Michiels S, Pailler E, Facchinetti F, Ou D, et al. A prospective examination of circulating tumor cell profiles in non-small-cell lung cancer molecular subgroups. Ann Oncol. 2017 Jul;28(7):1523-31.

Liu DG, Xue L, Li J, Yang Q, Peng JZ. Epithelialmesenchymal transition and GALC expression of circulating tumor cells indicate metastasis and poor prognosis in non-small cell lung cancer. Cancer Biomark. 2018;22(3): $417-26$.

Lou Y, Diao L, Cuentas ER, Denning WL, Chen L, Fan YH, et al. Epithelial-Mesenchymal Transition Is Associated with a Distinct Tumor Microenvironment Including Elevation of Inflammatory Signals and Multiple Immune Checkpoints in Lung Adenocarcinoma. Clin Cancer Res. 2016 Jul;22(14):363042.

Lowes LE, Allan AL. Circulating Tumor Cells and Implications of the Epithelial-to-Mesenchymal Transition. Adv Clin Chem. 2018;83: 121-81.

Lu J, Zhong Y, Chen J, Lin X, Lin Z, Wang N, et al. Radiation Enhances the Epithelial- Mesenchymal Transition of A549 Cells via miR35915p/USP33/PPM1A. Cell Physiol Biochem. 2018;50(2):721-33.

Maeng YI, Kim KH, Kim JY, Lee SJ, Sung WJ, Lee CK, et al. Transcription factors related to epithelial mesenchymal transition in tumor center and margin in invasive lung adenocarcinoma. Int J Clin Exp Pathol. 2014 Jun;7(7): 4095-103.
Mak G, Soria JC, Blagden SP, Plummer R, Fleming RA, Nebot N, et al. A phase Ib dose-finding, pharmacokinetic study of the focal adhesion kinase inhibitor GSK2256098 and trametinib in patients with advanced solid tumours. Br J Cancer. 2019 May;120(10):97581.

Mak MP, Tong P, Diao L, Cardnell RJ, Gibbons DL, William WN, et al. A Patient-Derived, Pan-Cancer EMT Signature Identifies Global Molecular Alterations and Immune Target Enrichment Following Epithelial-to-Mesenchymal Transition. Clin Cancer Res. 2016 Feb;22(3):609-20.

Maly V, Maly O, Kolostova K, Bobek V. Circulating Tumor Cells in Diagnosis and Treatment of Lung Cancer. In Vivo. 2019 Jul-Aug;33(4): 1027-37.

Manjunath Y, Upparahalli SV, Avella DM, Deroche CB, Kimchi ET, Staveley-O'Carroll KF, et al. PD-L1 Expression with Epithelial Mesenchymal Transition of Circulating Tumor Cells Is Associated with Poor Survival in Curatively Resected Non-Small Cell Lung Cancer. Cancers (Basel). 2019 Jun; 11(6):E806.

Markopoulos GS, Roupakia E, Marcu KB, Kolettas E. Epigenetic Regulation of Inflammatory Cytokine-Induced Epithelial-To-Mesenchymal Cell Transition and Cancer Stem Cell Generation. Cells. 2019 Sep;8(10):E1143.

Massard C, Azaro A, Soria JC, Lassen U, Le Tourneau C, Sarker D, et al. First-in-human study of LY3039478, an oral Notch signaling inhibitor in advanced or metastatic cancer. Ann Oncol. 2018 Sep;29(9):1911-7.

Matsubara D, Kishaba Y, Yoshimoto T, Sakuma Y, Sakatani T, Tamura T, et al. Immunohistochemical analysis of the expression of E-cadherin and ZEB1 in non-small cell lung cancer. Pathol Int. 2014 Nov;64(11):560-8.

Milano A, Mazzetta F, Valente S, Ranieri D, Leone L, Botticelli A, et al. Molecular Detection of EMT Markers in Circulating Tumor Cells from Metastatic Non-Small Cell Lung Cancer Patients: Potential Role in Clinical Practice. Anal Cell Pathol (Amst). 2018 Feb;2018: 3506874 .

Mitchell B, Dhingra JK, Mahalingam M. BRAF and Epithelial-Mesenchymal Transition: Lessons From Papillary Thyroid Carcinoma and Primary Cutaneous Melanoma. Adv Anat Pathol. 2016 Jul;23(4):244-71.

Mittal V. Epithelial Mesenchymal Transition in Tumor Metastasis. Annu Rev Pathol. 2018 Jan;13(1):395-412.

Mittal V, El Rayes T, Narula N, McGraw TE, Altorki NK, Barcellos-Hoff MH. The Microenvironment of Lung Cancer and Therapeutic Implications. Adv Exp Med Biol. 2016;890: $75-110$

Miyahara S, Hamasaki M, Hamatake D, Yamashita S, Shiraishi T, Iwasaki A, et al. Clinicopathological analysis of pleomorphic carcinoma of the lung: diffuse ZEB1 expression predicts poor survival. Lung Cancer. 2015 Jan;87(1): 39-44. 
Miyazono K, Katsuno Y, Koinuma D, Ehata S, Morikawa M. Intracellular and extracellular TGF- $\beta$ signaling in cancer: some recent topics. Front Med. 2018 Aug;12(4):387-411.

Miyoshi S, Kato T, Katayama H, Ito R, Mizuno Y, Okura T, et al. A case of EGFR mutant lung adenocarcinoma that acquired resistance to EGFR-tyrosine kinase inhibitors with MET amplification and epithelial-to-mesenchymal transition. Onco Targets Ther. 2015 Apr;8: 783-7.

Naghizadeh S, Mohammadi A, Baradaran B, Mansoori B. Overcoming multiple drug resistance in lung cancer using siRNA targeted therapy. Gene. 2019 Sep;714:143972.

Neal JW, Dahlberg SE, Wakelee HA, Aisner SC, Bowden M, Huang Y, et al.; ECOG-ACRIN 1512 Investigators. Erlotinib, cabozantinib, or erlotinib plus cabozantinib as second-line or third-line treatment of patients with EGFR wild-type advanced non-small-cell lung cancer (ECOG-ACRIN 1512): a randomised, controlled, open-label, multicentre, phase 2 trial. Lancet Oncol. 2016 Dec;17(12):166171.

Neelakantan D, Drasin DJ, Ford HL. Intratumoral heterogeneity: clonal cooperation in epithelial-to-mesenchymal transition and metastasis. Cell Adhes Migr. 2015;9(4):265-76.

Nicolazzo C, Gradilone A, Loreni F, Raimondi C, Gazzaniga P. EpCAMlow Circulating Tumor Cells: gold in the Waste. Dis Markers. 2019 Sep;2019:1718920.

Nokihara H, Nishio M, Yamamoto N, Fujiwara Y, Horinouchi H, Kanda S, et al. Phase 1 Study of Cabozantinib in Japanese Patients With Expansion Cohorts in Non-Small-Cell Lung Cancer. Clin Lung Cancer. 2019 May; 20(3):e317-28.

Noman MZ, Janji B, Abdou A, Hasmim M, Terry S, Tan TZ, et al. The immune checkpoint ligand PD-L1 is upregulated in EMT-activated human breast cancer cells by a mechanism involving ZEB-1 and miR-200. OncoImmunology. 2017 Jan;6(1):e1263412.

Ock CY, Kim S, Keam B, Kim M, Kim TM, Kim $\mathrm{JH}$, et al. PD-L1 expression is associated with epithelial-mesenchymal transition in head and neck squamous cell carcinoma. Oncotarget. 2016 Mar;7(13):15901-14.

Okita R, Maeda A, Shimizu K, Nojima Y, Saisho S, Nakata M. PD-L1 overexpression is partially regulated by EGFR/HER2 signaling and associated with poor prognosis in patients with non-small-cell lung cancer. Cancer Immunol Immunother. 2017 Jul;66(7):865-76.

Otaibi Z, Kamran A, Wegner RE, Colonias A, Weksler B, Finley GG. Trends in immunotherapy use and survival impact in stage IV non-small cell lung cancer. J Clin Oncol. 2019;37(15_suppl):e20715.

Otsuki Y, Saya H, Arima Y. Prospects for new lung cancer treatments that target EMT signaling. Dev Dyn. 2018 Mar;247(3):462-72.

Paik PK, Shen R, Berger MF, Ferry D, Soria JC, Mathewson A, et al. A Phase Ib Open-Label Multicenter Study of AZD4547 in Patients with Advanced Squamous Cell Lung Cancers. Clin Cancer Res. 2017 Sep;23(18):5366-73.

Pasquini G, Giaccone G. C-MET inhibitors for advanced non-small cell lung cancer. Expert Opin Investig Drugs. 2018 Apr;27(4):363-75.

Pastushenko I, Blanpain C. EMT Transition States during Tumor Progression and Metastasis. Trends Cell Biol. 2019 Mar;29(3):21226.

Patel S, Alam A, Pant R, Chattopadhyay S. Wnt signaling and its significance within the tumor microenvironment: novel therapeutic insights. Front Immunol. 2019 Dec;10:2872.

Paz-Ares L, Luft A, Vicente D, Tafreshi A, Gümüş M, Mazières J, et al.; KEYNOTE-407 Investigators. Pembrolizumab plus Chemotherapy for Squamous Non-Small-Cell Lung Cancer. N Engl J Med. 2018 Nov;379(21):2040-51.

Peters S, Zimmermann S. Management of Resistance to First-Line Anaplastic Lymphoma Kinase Tyrosine Kinase Inhibitor Therapy. Curr Treat Options Oncol. 2018 May;19(7):37.

Poh ME, Liam CK, Rajadurai P, Chai CS. Epithelial-to-mesenchymal transition (EMT) causing acquired resistance to afatinib in a patient with epidermal growth factor receptor (EGFR)-mutant lung adenocarcinoma. J Thorac Dis. 2018 Jul;10(7):E560-3.

Ramirez D, Kohar V, Lu M. Toward modeling context-specific EMT regulatory networks using temporal single cell RNA-Seq data. Front Mol Biosci. 2020 Apr;7:54.

Reckamp KL, Gardner BK, Figlin RA, Elashoff D, Krysan K, Dohadwala M, et al. Tumor response to combination celecoxib and erlotinib therapy in non-small cell lung cancer is associated with a low baseline matrix metalloproteinase- 9 and a decline in serum-soluble E-cadherin. J Thorac Oncol. 2008 Feb;3(2): $117-24$.

Reckamp KL, Koczywas M, Cristea MC, Dowell JE, Wang HJ, Gardner BK, et al. Randomized phase 2 trial of erlotinib in combination with high-dose celecoxib or placebo in patients with advanced non-small cell lung cancer. Cancer. 2015 Sep;121(18):3298-306.

Rho JK, Choi YJ, Lee JK, Ryoo BY, Na II, Yang SH, et al. Epithelial to mesenchymal transition derived from repeated exposure to gefitinib determines the sensitivity to EGFR inhibitors in A549, a non-small cell lung cancer cell line. Lung Cancer. 2009 Feb;63(2):219-26.

Rotow J, Bivona TG. Understanding and targeting resistance mechanisms in NSCLC. Nat Rev Cancer. 2017 Oct;17(11):637-58.

Rudisch A, Dewhurst MR, Horga LG, Kramer N, Harrer N, Dong M, et al. High EMT Signature Score of Invasive Non-Small Cell Lung Cancer (NSCLC) Cells Correlates with NFkB Driven Colony-Stimulating Factor 2 (CSF2/GMCSF) Secretion by Neighboring Stromal Fibroblasts. PLoSOne.2015 Apr;10(4):e0124283.

Sawabata N, Susaki Y, Nakamura T, Kawaguchi T, Yasukawa M, Taniguchi S. Cluster circulating tumor cells in surgical cases of lung cancer. Gen Thorac Cardiovasc Surg. 2020. DOI: 10.1007/s11748-020-01308-3.
Schramm A, Opitz I, Thies S, Seifert B, Moch H, Weder W, et al. Prognostic significance of epithelial-mesenchymal transition in malignant pleural mesothelioma. Eur J Cardiothorac Surg. 2010 Mar;37(3):566-72.

SenthilKumar G, Fisher MM, Skiba JH, Miller MC, Brennan SR, Kaushik S, et al. FGFR Inhibition Enhances Sensitivity to Radiation in Non-Small Cell Lung Cancer. Mol Cancer Ther. 2020 Jun;19(6):1255-65.

Sequist LV, Waltman BA, Dias-Santagata D, Digumarthy S, Turke AB, Fidias P, et al. Genotypic and histological evolution of lung cancers acquiring resistance to EGFR inhibitors. Sci Transl Med. 2011 Mar;3(75):75ra26.

Sesumi Y, Suda K, Mizuuchi H, Kobayashi Y, Sato $\mathrm{K}$, Chiba M, et al. Effect of dasatinib on EMTmediated-mechanism of resistance against EGFR inhibitors in lung cancer cells. Lung Cancer. 2017 Feb;104:85-90.

Shao B, Bjaanæs MM, Helland Å, Schütte C, Conrad T. EMT network-based feature selection improves prognosis prediction in lung adenocarcinoma.PLoS One.2019Jan;14(1):e0204186.

Shaurova T, Zhang L, Goodrich DW, Hershberger PA. Understanding Lineage Plasticity as a Path to Targeted Therapy Failure in EGFRMutant Non-small Cell Lung Cancer. Front Genet. 2020 Mar;11:281.

Shen W, Pang H, Liu J, Zhou J, Zhang F, Liu L, et al. Epithelial-mesenchymal transition contributes to docetaxel resistance in human non-small cell lung cancer. Oncol Res. 2014; 22(1):47-55.

Singh A, Greninger P, Rhodes D, Koopman L, Violette S, Bardeesy N, et al. A gene expression signature associated with "K-Ras addiction" reveals regulators of EMT and tumor cell survival. Cancer Cell. 2009 Jun;15(6):489-500.

Singh PK, Silakari O. Chemotherapeutics-resistance "arms" race: an update on mechanisms involved in resistance limiting EGFR inhibitors in lung cancer. Life Sci. 2017 Oct; 186: 25-32.

Soria JC, Ohe Y, Vansteenkiste J, Reungwetwattana $\mathrm{T}$, Chewaskulyong $\mathrm{B}$, Lee $\mathrm{KH}$, et al.; FLAURA Investigators. Osimertinib in Untreated EGFR-Mutated Advanced NonSmall-Cell Lung Cancer. N Engl J Med. 2018 Jan;378(2):113-25.

Soucheray M, Capelletti M, Pulido I, Kuang Y, Paweletz CP, Becker JH, et al. Intratumoral Heterogeneity in EGFR-Mutant NSCLC Results in Divergent Resistance Mechanisms in Response to EGFR Tyrosine Kinase Inhibition. Cancer Res. 2015 Oct;75(20):4372-83.

Soundararajan R, Fradette JJ, Konen JM, Moulder S, Zhang X, Gibbons DL, et al. Targeting the Interplay between Epithelial-to-Mesenchymal-Transition and the Immune System for Effective Immunotherapy. Cancers (Basel). 2019 May;11(5):E714.

Sow HS, Ren J, Camps M, Ossendorp F, Ten Dijke P. Combined Inhibition of TGF- $\beta$ Signaling and the PD-L1 Immune Checkpoint Is Differentially Effective in Tumor Models. Cells. 2019 Apr;8(4):E320. 
Suda K, Rozeboom L, Rivard CJ, Yu H, Ellison K, Melnick MA, et al. Therapy-induced E-cadherin downregulation alters expression of programmed death ligand-1 in lung cancer cells. Lung Cancer. 2017 Jul;109:1-8.

Suda K, Tomizawa K, Fujii M, Murakami H, Osada H, Maehara Y, et al. Epithelial to mesenchymal transition in an epidermal growth factor receptor-mutant lung cancer cell line with acquired resistance to erlotinib. J Thorac Oncol. 2011 Jul;6(7):1152-61.

Syrigos K, Fiste O, Charpidou A, Grapsa D. Circulating tumor cells count as a predictor of survival in lung cancer. Crit Rev Oncol Hematol. 2018 May;125:60-8.

Takada K, Toyokawa G, Shoji F, Okamoto T, Maehara Y. The Significance of the PD-L1 Expression in Non-Small-Cell Lung Cancer: Trenchant Double Swords as Predictive and Prognostic Markers. Clin Lung Cancer. 2018 Mar;19(2):120-9.

Thomas VT, Hinson S, Konduri K. Epithelialmesenchymal transition in pulmonary carcinosarcoma: case report and literature review. Ther Adv Med Oncol. 2012 Jan;4(1):31-7.

Thompson JC, Hwang WT, Davis C, Deshpande C, Jeffries S, Rajpurohit Y, et al. Gene signatures of tumor inflammation and epithelialto-mesenchymal transition (EMT) predict responses to immune checkpoint blockade in lung cancer with high accuracy. Lung Cancer. 2020 Jan;139:1-8.

Tièche CC, Peng RW, Dorn P, Froment L, Schmid RA, Marti TM. Prolonged pemetrexed pretreatment augments persistence of cisplatininduced DNA damage and eliminates resistant lung cancer stem-like cells associated with EMT. BMC Cancer. 2016 Feb;16(1):125.

Toge M, Yokoyama S, Kato S, Sakurai H, Senda K, Doki Y, et al. Critical contribution of MCL-1 in EMT-associated chemo-resistance in A549 non-small cell lung cancer. Int J Oncol. 2015 Apr;46(4):1844-8.

Togo S, Katagiri N, Namba Y, Tulafu M, Nagahama K, Kadoya K, et al. Sensitive detection of viable circulating tumor cells using a novel conditionally telomerase-selective replicating adenovirus in non-small cell lung cancer patients. Oncotarget. 2017 May;8(21):3488495.

Tsoukalas N, Aravantinou-Fatorou E, Tolia M, Giaginis C, Galanopoulos M, Kiakou M, et al. Epithelial-Mesenchymal Transition in Non Small-cell Lung Cancer. Anticancer Res. 2017 Apr;37(4):1773-8.

Tulchinsky E, Demidov O, Kriajevska M, Barlev NA, Imyanitov E. EMT: A mechanism for escape from EGFR-targeted therapy in lung cancer. Biochim Biophys Acta Rev Cancer. 2019 Jan;1871(1):29-39.

Uprety D, Mandrekar SJ, Wigle D, Roden AC, Adjei AA. Neoadjuvant Immunotherapy for Non-Small Cell Lung Cancer - Current Concepts and Future Approaches. J Thorac Oncol. 2020 Jun;S1556-0864(20)30425-1.

Urbanska EM, Sørensen JB, Melchior LC, Costa JC, Santoni-Rugiu E. Changing ALK-TKI-Resis- tance Mechanisms in Rebiopsies of ALK-Rearranged NSCLC: ALK- and BRAF-Mutations Followed by Epithelial-Mesenchymal Transition. Int J Mol Sci. 2020 Apr;21(8):E2847.

van Staalduinen J, Baker D, Ten Dijke P, van Dam H. Epithelial-mesenchymal-transitioninducing transcription factors: new targets for tackling chemoresistance in cancer? Oncogene. 2018 Nov;37(48):6195-211.

Villalobos M, Czapiewski P, Reinmuth N, Fischer JR, Andreas S, Kortsik C, et al. Impact of EMT in stage IIIB/IV NSCLC treated with erlotinib and bevacizumab when compared with cisplatin, gemcitabine and bevacizumab. Oncol Lett. 2019 Jun;17(6):4891-900.

Voena C, Varesio LM, Zhang L, Menotti M, Poggio T, Panizza E, et al. Oncogenic ALK regulates EMT in non-small cell lung carcinoma through repression of the epithelial splicing regulatory protein 1 . Oncotarget. 2016 May; 7(22):33316-30.

Wakelee HA, Gettinger S, Engelman J, Jänne PA, West H, Subramaniam DS, et al. A phase Ib/ II study of cabozantinib (XL184) with or without erlotinib in patients with non-small cell lung cancer. Cancer Chemother Pharmacol. 2017 May;79(5):923-32.

Wang F, Liu X, Bartholdy BA, Cheng H, Halmos B. Blockade of AXL activation overcomes acquired resistance to EGFR tyrosine kinase inhibition in non-small cell lung cancer. Transl Cancer Res. 2019;8(6):2425-38.

Wang Y, Liu Y, Zhang L, Tong L, Gao Y, Hu F, et al. Vimentin expression in circulating tumor cells (CTCs) associated with liver metastases predicts poor progression-free survival in $\mathrm{pa}$ tients with advanced lung cancer. J Cancer Res Clin Oncol. 2019 Dec;145(12):2911-20.

Wang Y, Xia H, Zhuang Z, Miao L, Chen X, Cai $\mathrm{H}$. Axl-altered microRNAs regulate tumorigenicity and gefitinib resistance in lung cancer. Cell Death Dis. 2014 May;5(5):e1227.

Wang Z, Yang MQ, Lei L, Fei LR, Zheng YW, Huang WJ, et al. Overexpression of KRT17 promotes proliferation and invasion of nonsmall cell lung cancer and indicates poor prognosis. Cancer Manag Res. 2019 Aug;11: 7485-97.

Wei J, van der Wekken AJ, Saber A, Terpstra MM, Schuuring E, Timens W, et al. Mutations in EMT-Related Genes in ALK Positive Crizotinib Resistant Non-Small Cell Lung Cancers. Cancers (Basel). 2018 Jan;10(1):E10.

Wheatley-Price P, Gadgeel S, Takahashi T, Li X, Dar M, Blumenschein GR Jr. Phase 1b/2 Randomized Study of MEDI-575 in Combination With Carboplatin Plus Paclitaxel Versus Carboplatin Plus Paclitaxel Alone in Adult Patients With Previously Untreated Advanced Non-Small-Cell Lung Cancer. Clin Lung Cancer. 2019 May;20(3):e362-8.

Witta SE, Gemmill RM, Hirsch FR, Coldren CD, Hedman K, Ravdel L, et al. Restoring E-cadherin expression increases sensitivity to epidermal growth factor receptor inhibitors in lung cancer cell lines. Cancer Res. 2006 Jan; 66(2):944-50
Witta SE, Jotte RM, Konduri K, Neubauer MA, Spira AI, Ruxer RL, et al. Randomized phase II trial of erlotinib with and without entinostat in patients with advanced non-small-cell lung cancer who progressed on prior chemotherapy. J Clin Oncol. 2012 Jun;30(18):224855.

Wong SH, Fang CM, Chuah LH, Leong CO, Ngai SC. E-cadherin: its dysregulation in carcinogenesis and clinical implications. Crit Rev Oncol Hematol. 2018 Jan;121:11-22.

Woodard GA, Jones KD, Jablons DM. Lung Cancer Staging and Prognosis. Cancer Treat Res. 2016;170:47-75.

Wu S, Liu S, Liu Z, Huang J, Pu X, Li J, et al. Classification of circulating tumor cells by epithelial-mesenchymal transition markers. PLoS One. 2015 Apr;10(4):e0123976.

Wushou A, Hou J, Zhao YJ, Shao ZM. Twist-1 upregulation in carcinoma correlates to poor survival. Int J Mol Sci. 2014 Nov; 15(12): 21621-30.

Xia L, Liu Y, Wang Y. PD-1/PD-L1 Blockade Therapy in Advanced Non-Small-Cell Lung Cancer: Current Status and Future Directions. Oncologist. 2019 Feb;24(S1 Suppl 1):S31-41.

Xie M, He CS, Wei SH, Zhang L. Notch-1 contributes to epidermal growth factor receptor tyrosine kinase inhibitor acquired resistance in non-small cell lung cancer in vitro and in vivo. Eur J Cancer. 2013 Nov;49(16):3559_ 72.

Yang H, Liang SQ, Schmid RA, Peng RW. New Horizons in KRAS-Mutant Lung Cancer: Dawn After Darkness. Front Oncol. 2019 Sep; 9:953

Yang J, Antin P, Berx G, Blanpain C, Brabletz T, Bronner M, et al.; EMT International Association (TEMTIA). Guidelines and definitions for research on epithelial-mesenchymal transition. Nat Rev Mol Cell Biol. 2020 Jun; 21(6):341-52.

Yang MH, Wu KJ. TWIST activation by hypoxia inducible factor-1 (HIF-1): implications in metastasis and development. Cell Cycle. 2008 Jul;7(14):2090-6.

Yao YH, Cui Y, Qiu XN, Zhang LZ, Zhang W, Li $\mathrm{H}$, et al. Attenuated LKB1-SIK1 signaling promotes epithelial-mesenchymal transition and radioresistance of non-small cell lung cancer cells. Chin J Cancer. 2016 Jun;35(1): 50.

Yin J, Hu W, Xue X, Fu W, Dai L, Jiang Z, et al. Epigenetic activation of hepatocyte growth factor is associated with epithelial-mesenchymal transition and clinical outcome in nonsmall cell lung cancer. J Cancer. 2019 Aug; 10(21):5070-81.

Yuan X, Wu H, Han N, Xu H, Chu Q, Yu S, et al. Notch signaling and EMT in non-small cell lung cancer: biological significance and therapeutic application. J Hematol Oncol. 2014 Dec;7(1):87.

Zeisberg M, Neilson EG. Biomarkers for epithelial-mesenchymal transitions. J Clin Invest. 2009 Jun;119(6):1429-37. 
Zhang H, Liu J, Yue D, Gao L, Wang D, Zhang H, et al. Clinical significance of E-cadherin, $\beta$-catenin, vimentin and S100A4 expression in completely resected squamous cell lung carcinoma. J Clin Pathol. 2013 Nov;66(11): 937-45.

Zhang N, Wang D, Li X, Yang Z, Zhang G, Wang $\mathrm{Y}$, et al. A case report of EGFR mutant lung adenocarcinoma that acquired resistance to EGFR-tyrosine kinase inhibitors with T790M mutation and epithelial-to-mesenchymal transition. Respir Med Case Rep. 2017 Aug; 22:183-6.

Zhang Q, Liu S, Parajuli KR, Zhang W, Zhang K, Mo Z, et al. Interleukin-17 promotes prostate cancer via MMP7-induced epithelial-tomesenchymal transition. Oncogene. 2017 Feb;36(5):687-99.
Zhang Z, Lee JC, Lin L, Olivas V, Au V, LaFramboise $\mathrm{T}$, et al. Activation of the AXL kinase causes resistance to EGFR-targeted therapy in lung cancer. Nat Genet. 2012 Jul;44(8):85260.

Zhao M, Liu Y, Liu R, Qi J, Hou Y, Chang J, et al. Upregulation of IL-11, an IL-6 Family Cytokine, Promotes Tumor Progression and Correlates with Poor Prognosis in Non-Small Cell Lung Cancer. Cell Physiol Biochem. 2018; 45(6):2213-24.

Zheng H, Kang Y. Multilayer control of the EMT master regulators. Oncogene. 2014 Apr;33 (14):1755-63.

Zheng X, Lu G, Yao Y, Gu W. An Autocrine IL-6/ IGF-1R Loop Mediates EMT and Promotes Tumor Growth in Non-small Cell Lung Cancer. Int J Biol Sci. 2019 Jul;15(9):1882-91.
Zhou J, Wang J, Zeng Y, Zhang X, Hu Q, Zheng $\mathrm{J}$, et al. Implication of epithelial-mesenchymal transition in IGF1R-induced resistance to EGFR-TKIs in advanced non-small cell lung cancer. Oncotarget. 2015 Dec;6(42):4433245.

Zhu C, Wei Y, Wei X. AXL receptor tyrosine kinase as a promising anti-cancer approach: functions, molecular mechanisms and clinical applications. Mol Cancer. 2019 Nov; 18(1): 153.

Zhu X, Chen L, Liu L, Niu X. EMT-Mediated Acquired EGFR-TKI Resistance in NSCLC: mechanisms and Strategies. Front Oncol. 2019 Oct;9:1044.

Zoni E, van der Pluijm G, Gray PC, Kruithof-de Julio M. Epithelial Plasticity in Cancer: Unmasking a MicroRNA Network for TGF- $\beta$-, Notch-, and Wnt-Mediated EMT. J Oncol. 2015;2015:198967. 